\title{
Myosin VI small insert isoform maintains exocytosis by tethering secretory granules to the cortical actin
} \author{
John Kendrick-Jones, ${ }^{3}$ Folma Buss, ${ }^{4}$ and Frédéric A. Meunier ${ }^{1}$ \\ 'Queensland Brain Institute, The University of Queensland, Brisbane, Queensland 4072, Australia \\ 2 Omics Laboratory, Mater Health Services Pathology, Mater Adult Hospital, Brisbane, Queensland 4101, Australia \\ ${ }^{3}$ Medical Research Council Laboratory of Molecular Biology, Cambridge CB2 OQH, England, UK \\ ${ }^{4}$ Cambridge Institute for Medical Research, University of Cambridge, Cambridge CB2 OXY, England, UK
}

Vanesa M. Tomatis, ${ }^{1}$ Andreas Papadopulos, ${ }^{1}$ Nancy T. Malintan, ${ }^{1}$ Sally Martin, ${ }^{1}$ Tristan Wallis, ${ }^{2}$ Rachel S. Gormal,

\section{Introduction}

In neurosecretory cells, secretory granules (SGs) containing neuropeptides and hormones fuse with the plasma membrane and release their contents into the extracellular space (Bader et al., 2002; Dernick et al., 2003; Becherer and Rettig, 2006; Neher, 2006; Westerink and Ewing, 2008). Before undergoing exocytosis, SGs need to pass through the physical barrier imposed by the cortical actin network. This network plays a dual role in neuroexocytosis. It first acts as a barrier for SGs, which is dissipated in response to $\mathrm{Ca}^{2+}$ influx through the action of proteins such as scinderins (Vitale et al., 1991; Lejen et al., 2002). It then plays a more active role, regulated by intersectin-1, cdc42 (Gasman et al., 2004; Malacombe et al., 2006), and phosphatidylinositol(4,5)bisphosphate (Wen et al., 2011), in promoting SG transport to the plasma membrane (Gasman et al., 2004; Malacombe et al., 2006; Wen et al., 2011). However, the mechanism whereby SGs are recruited to the cortical actin network and how this process helps to regulate diverse pools

A. Papadopulos and N.T. Malintan contributed equally to this paper.

Correspondence to Frédéric A. Meunier: f.meunier@uq.edu.au

Abbreviations used in this paper: CSV, comma separated variable; hPLAP, human placental alkaline phosphatase; MALDI, matrix-assisted laser desorption ionization; MS, mass spectrometry; MSD, mean square displacement; $\mathrm{m} / \mathrm{z}$, mass per charge; NI, no insert; NPY, neuropeptide Y; PSS, physiological saline solution; SG, secretory granule; SI, small insert; TFA, trifluoroacetic acid; TFE, trifluoroethanol; TIRF, total internal reflection fluorescence; TOF, time of flight. consistent with a replenishment defect. This exocytic defect was selectively rescued by expression of the myosin VI small insert (SI) isoform, which efficiently tethered SGs to the cortical actin network. These myosin VI SI-specific effects were prevented by deletion of a c-Src kinase phosphorylation DYD motif, identified in silico. Myosin VI SI thus recruits SGs to the cortical actin network, potentially via c-Src phosphorylation, thereby maintaining an active pool of SGs near the plasma membrane. of SGs are currently unknown. The goal of this study was to identify cytosolic proteins that interact with $\mathrm{SGs}$ in a $\mathrm{Ca}^{2+}$ dependent manner, thereby demonstrating the molecular mechanism underlying activity-dependent mobilization of SGs to the cortical actin network.

To address this, we established an organelle pull-down protocol using purified SGs as bait, coupled to mass spectrometry (MS) to identify cytosolic proteins recruited to SGs in a $\mathrm{Ca}^{2+}$ dependent manner. One of the identified proteins was myosin VI. This motor protein is unique as, in addition to playing an important anchoring role (Self et al., 1999), its directionality along actin filaments runs counter to other myosin proteins (Wells et al., 1999; Bryant et al., 2007). Four alternatively spliced isoforms of myosin VI have been identified containing either a large insert (21-31 aa), a small insert (SI; 9 aa), no insert (NI), or both inserts within the C-terminal tail, located in the cargobinding domain (Buss et al., 2001; Au et al., 2007). These isoforms are differentially expressed in tissues and cell lines and are associated with specific subcellular compartments and a host of cellular functions (Buss et al., 2001; Au et al., 2007; Puri, 2009).

(c) 2013 Tomatis et al. This article is distributed under the terms of an AttributionNoncommercial-Share Alike-No Mirror Sites license for the first six months after the publication date (see http://www.rupress.org/terms). After six months it is available under a Creative Commons License (Attribution-Noncommercial-Share Alike 3.0 Unported license, as described at http://creativecommons.org/licenses/by-nc-sa/3.0/). 

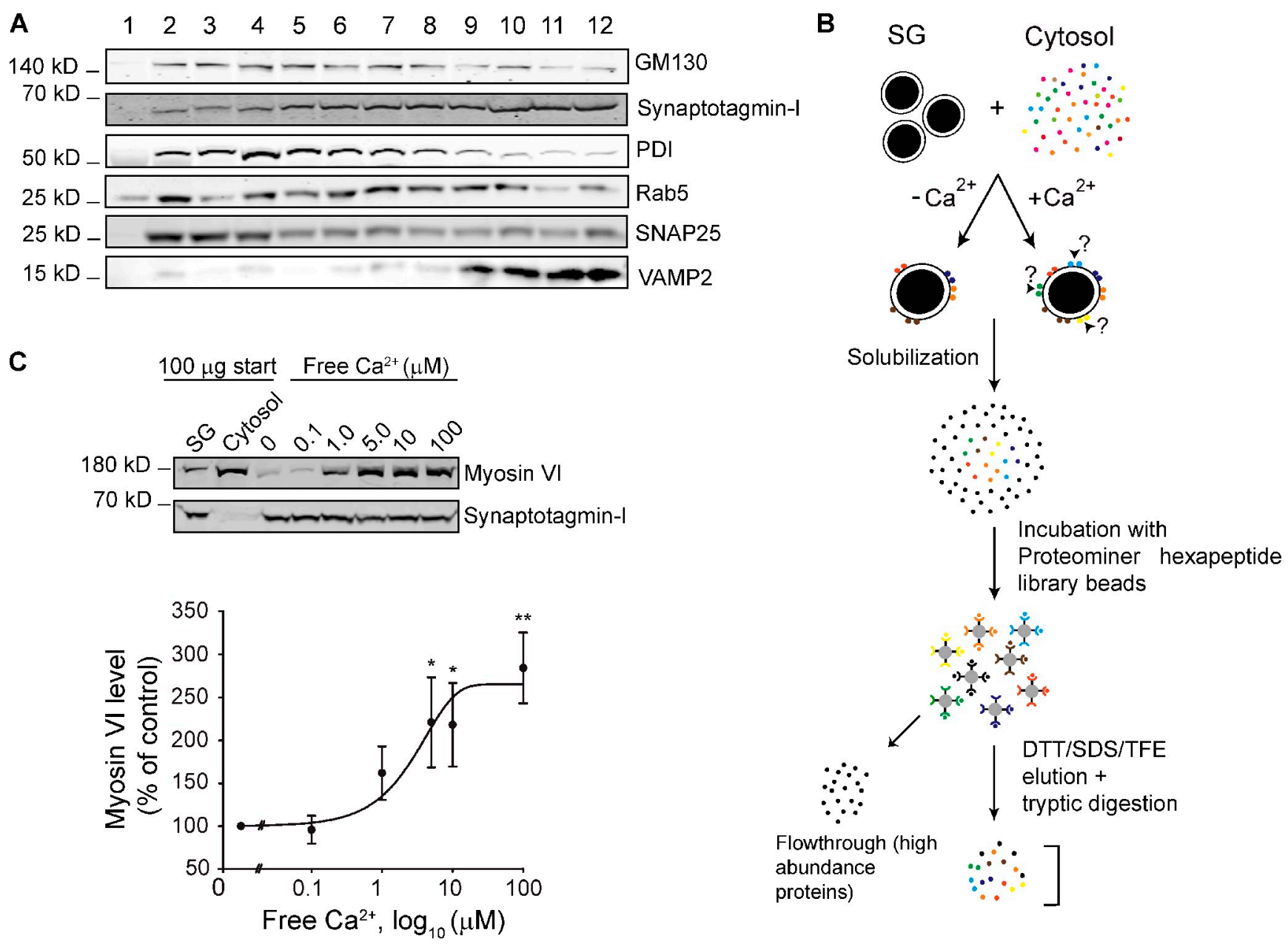

Flowthrough (high abundance proteins)

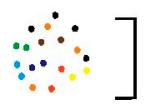

D Myosin VI

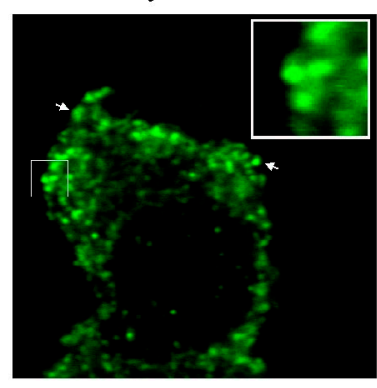

$\mathbf{E}$

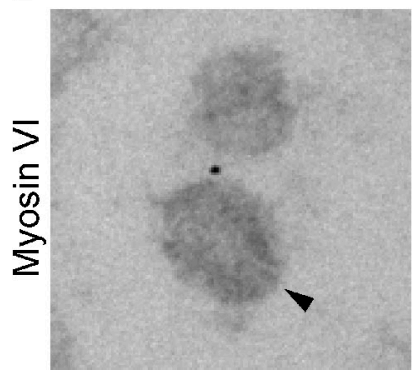

\section{Synaptotagmin-I}
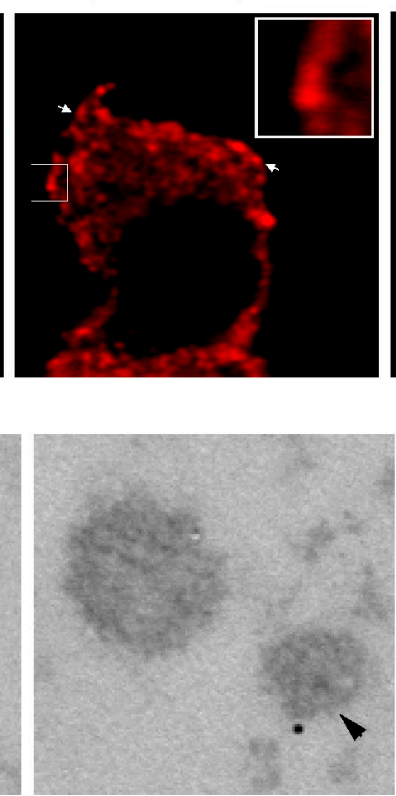
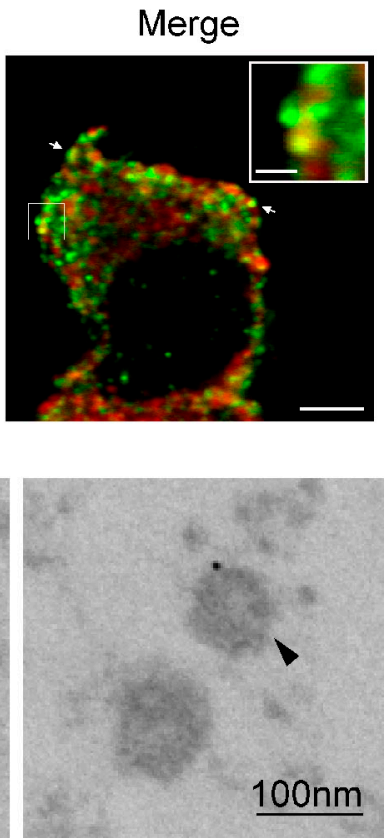

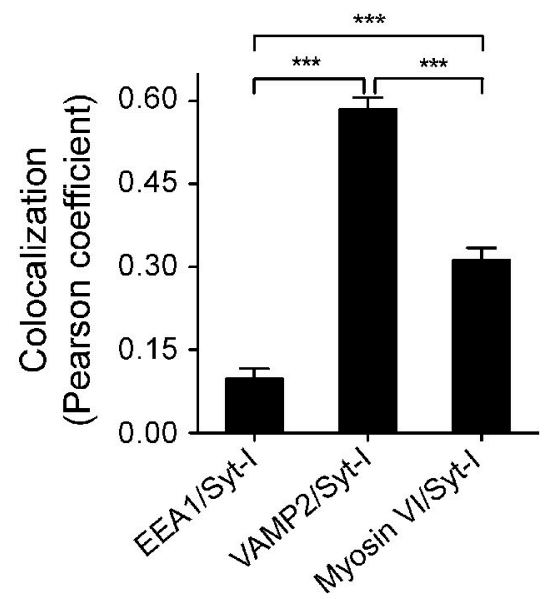

Figure 1. Myosin VI interacts with SGs in a $\mathrm{Ca}^{2+}$-dependent manner. (A) Bovine adrenal medulla fractionation was assessed by SDS-PAGE and Western blotting with the indicated antibodies (Golgi: GM130; early endosomes: Rab5; endoplasmic reticulum: protein disulfide-isomerase (PDI); plasma membrane: SNAP25; and SG: Synaptotagmin-I and VAMP2). Purified SGs were obtained by pooling fractions 11 and 12. (B) Schematic representation of the experimental approach used to identify cytosolic proteins interacting with SGs in a $\mathrm{Ca}^{2+}$-dependent manner. (C, top) Purified SGs and cytosol were incubated in the presence of increasing free $\left[\mathrm{Ca}^{2+}\right]$. Myosin VI recruitment to SGs was analyzed by Western blotting. Synaptotagmin-l was used as a loading control. (bottom) Quantification of myosin VI recruitment to SGs $(n=3)$. (D, left) PCl 2 cells immunolabeled with anti-myosin VI (green) and 
Table 1. Myosin VI peptide sequence obtained from peptide mass and fragmentation data analysis

\begin{tabular}{|c|c|c|c|c|c|c|}
\hline Myosin VI peptides & Observed & Experimental $M_{r}$ & Calculated $M_{r}$ & ppm & Miss & Score \\
\hline D.LKENIAIVER.R + deamidated (NQ) & $1,185.6534$ & $1,184.6462$ & $1,184.6764$ & -25.55 & 1 & 44 \\
\hline $\begin{array}{l}\text { T.RMQAQARGQLMR.I + three } \\
\text { deamidated (NQ); two oxidation (M) }\end{array}$ & $1,480.7603$ & $1,479.753$ & $1,479.6922$ & 41.10 & 2 & 29 \\
\hline $\begin{array}{l}\text { S.LQSLLKDTQIQLDDAVR.A + three } \\
\text { deamidated (NQ) }\end{array}$ & $1,958.9742$ & $1,957.9669$ & $1,958.0208$ & -27.51 & 1 & 31 \\
\hline $\begin{array}{l}\text { S.SFQTVSALHRENLNKLMTNLR.T + } \\
\text { deamidated (NQ) }\end{array}$ & $2,473.2018$ & $2,472.1945$ & $2,472.2907$ & -38.91 & 2 & 22 \\
\hline
\end{tabular}

A Mascot ion score $>25$ represents a peptide with an extensive homology to the sequence in the database. $M_{r}$, related molecular weight; ppm, parts per million mass accuracy; Miss, number of missed tryptic cleavages; Score, Mascot ion score.

Although myosin VI has recently been shown to be important for synaptic function in the Drosophila melanogaster neuromuscular junction (Kisiel et al., 2011), its precise role in neurosecretory cells remains to be elucidated, with its involvement in regulated secretion in these cells recently being questioned (Majewski et al., 2011). Here, we reveal a novel role for the myosin VI SI in tethering SGs to F-actin in response to stimulation. We also demonstrate that this process is required for the maintenance of regulated neuroexocytosis in PC12 cells and is possibly controlled by c-Src kinase through the phosphorylation of a single DYD motif solely present in this isoform.

\section{Results}

Myosin VI interacts with SGs in a $\mathrm{Ca}^{2+}$-dependent manner

To identify the cytosolic proteins that are recruited to SGs in a $\mathrm{Ca}^{2+}$-dependent manner, purified SGs and cytosol were prepared from bovine adrenal medulla (Smith and Winkler, 1967; Simon et al., 1988; Meunier et al., 2005). Fractions enriched in SGs (11 and 12) were identified by the presence of Synaptotagmin-I and VAMP2 and pooled (referred to hereafter as purified SGs; Fig. 1 A; Brose et al., 1992; Papini et al., 1995). Purified SGs and cytosol were then mixed in the presence or absence of $100 \mu \mathrm{M}$ free $\mathrm{Ca}^{2+}$ (Fig. 1 B; Osborne et al., 2008). After washing and solubilization, samples were incubated with ProteoMiner beads to increase the detection of low abundance proteins (Bellei et al., 2011; Fonslow et al., 2011). The eluate from the ProteoMiner beads was digested with trypsin and analyzed by MS (Fig. 1 B). Identified proteins were classified based on their MS protein score with or without $\mathrm{Ca}^{2+}$ (Table S1). One interesting cytosolic protein, the score of which was highly increased in the presence of $\mathrm{Ca}^{2+}$, was myosin VI (Table 1). The $\mathrm{Ca}^{2+}$-dependent recruitment of myosin VI to purified SGs was confirmed by Western blotting (Fig. 1 C). We also analyzed the colocalization between Synaptotagmin-1-labeled SGs and either myosin VI, EEA1 (an early endosome marker), or VAMP2 in PC12 cells (Fig. 1 D). This analysis revealed a threefold higher Pearson correlation coefficient between myosin VI/Synaptotagmin-1 compared with
EEA1/Synaptotagmin-1 ( $\mathrm{P}<0.001)$. The association of myosin VI with SGs was also confirmed using immunoelectron microscopy (Fig. 1 E, 2.48\% SG myosin VI positive compared with $0.65 \%$ for control $\mathrm{IgG})$.

\section{Myosin VI tethers SGs to the cortical actin network in PC12 cells and is required to sustain regulated exocytosis}

To analyze the role of myosin VI in the SG dynamics and regulated exocytosis in PC12 cells, we reduced its expression level using an shRNA knockdown strategy. Two different shRNAs (sh2- and sh3-RNA), which target highly conserved N-terminal sequences present in all myosin VI isoforms, were used. Using these shRNAs, total myosin VI expression was depleted by 50-60\% compared with untransfected cells or a scrambled sequence (Fig. 2 A). Using total internal reflection fluorescence (TIRF) microscopy, we analyzed the distribution and movement of SGs after myosin VI knockdown in cells expressing neuropeptide Y (NPY)-mCherry, as an SG marker. Myosin VI knockdown significantly reduced the number of SGs near the plasma membrane both before and after nicotine stimulation (Fig. 2, B and C) but did not affect the average speed of the SGs (Fig. 2 D). This suggested that reduced myosin VI expression results in either a defect in the retention of SGs near the plasma membrane or a reduction in SG biogenesis. However, myosin VI knockdown did not affect the level (Fig. S1 A) or distribution of Synaptotagmin-1 (Fig. S1 B). Furthermore, the Golgi complex morphology (Fig. S1 C) was not perturbed, suggesting that the reduced SG density detected in the TIRF region of myosin VI knockdown cells results from a defect in SG anchoring to the cortical actin network rather than from decreased SG biogenesis.

Given the lack of effect on the average speed of SGs (Fig. 2 D), myosin VI is unlikely to be implicated in generating their movement but could be involved in tethering SG to the cortical actin network as they are progressing toward the plasma membrane. To test this hypothesis, we analyzed a selected population of nonresident SGs appearing in the TIRF plane and undergoing movement toward the plasma membrane. The mean

anti-Synaptotagmin-I (red) antibodies. Arrows mark colabeled SGs. The enlarged images (insets) show the association between endogenous myosin VI and Synaptotagmin-I. Bars: (main images) $5 \mu \mathrm{m}$; (insets) $1 \mu \mathrm{m}$. (right) Analysis of the colocalization between Synaptotagmin-l (Syt-l) and myosin VI, EEA 1 , or VAMP2. (E) Paraformaldehyde-fixed PC12 cells were immunolabeled with the anti-myosin VI antibody and labeled with 5-nm protein A-gold for EM. Arrowheads show myosin VI-positive SGs. Error bars are means $\pm \mathrm{SEM} .{ }^{*}, \mathrm{P}<0.05 ;{ }^{*}, \mathrm{P}<0.01 ;{ }^{* *}, \mathrm{P}<0.001$. 
A
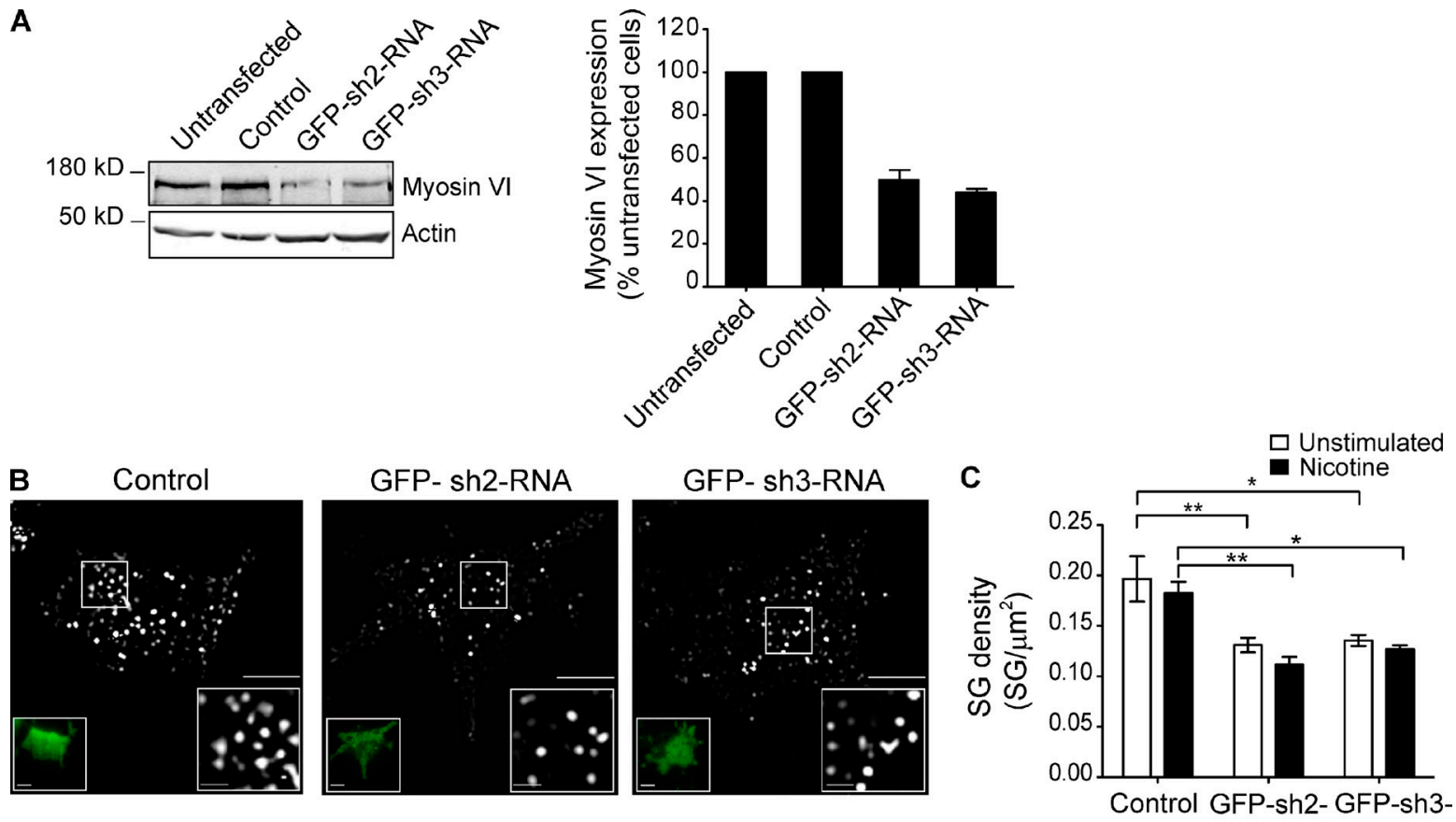

D

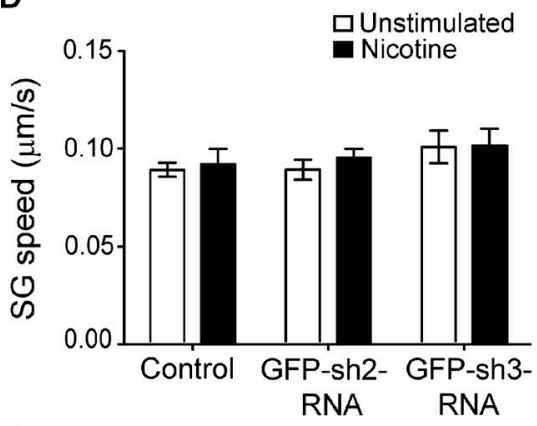

E RNA RNA
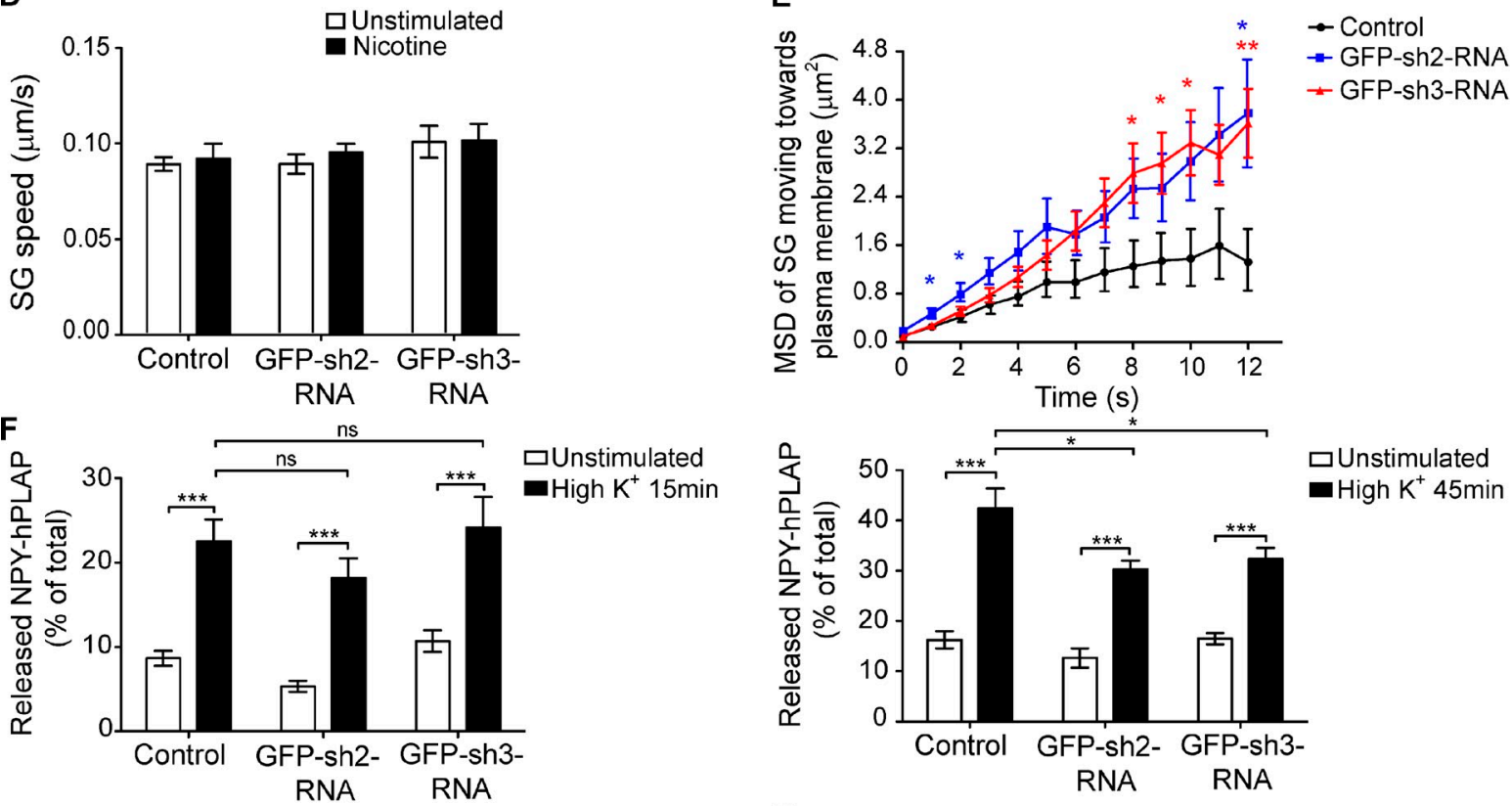

H
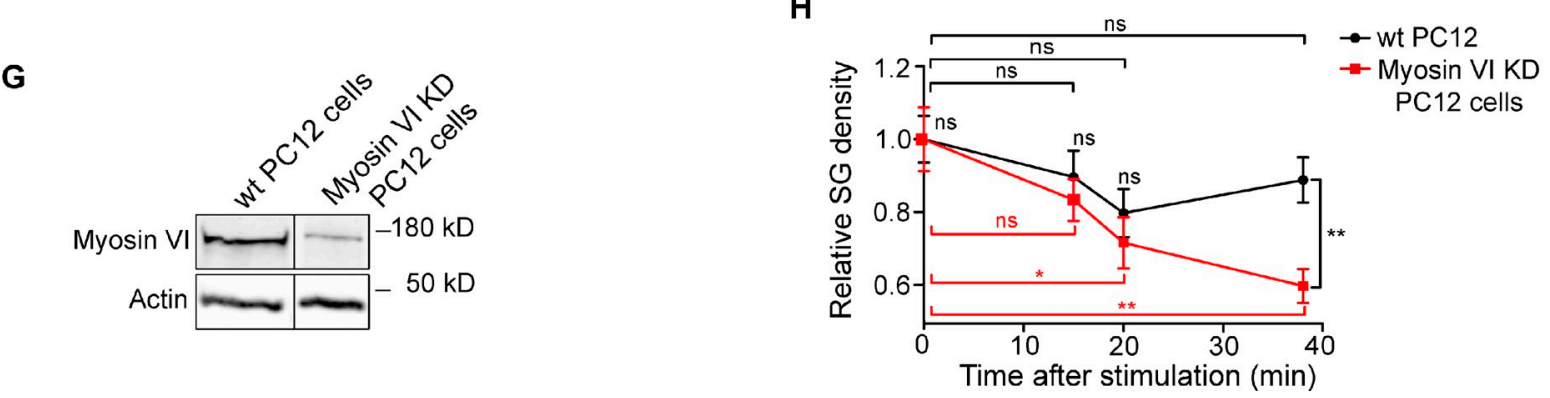

Figure 2. Myosin VI knockdown impairs the maintenance of exocytosis. (A, left) Analysis of myosin $\mathrm{VI}$ expression levels by Western blotting with an anti-myosin VI antibody in untransfected PC12 cells, cells transfected with GFP-scrambled shRNA (control), and cells transfected with GFP-shRNA against myosin VI (GFP-sh2-RNA and GFP-sh3-RNA). Anti- $\beta$-actin was used as a loading control. (right) Quantification of the expression level of myosin VI ( $n=6$ ). (B) TIRF images of NPY-mCherry (pseudocolored gray) in PC12 cotransfected with GFP-scrambled-shRNA (control), GFP-sh2-RNA, or GFP-sh3-RNA. Left insets show the respective GFP-shRNA expression. The enlarged images on the right highlight a fixed area for comparison of SG density. Bars: (main images and left insets) $5 \mu \mathrm{m}$; (right insets) $1 \mu \mathrm{m}$. (C and D) SG density (C) and SG average speed (D) in the TIRF plane quantified in the condition shown 
square displacement (MSD) was evaluated in control and myosin VI knockdown PC12 cells after stimulation (Fig. 2 E). In myosin VI knockdown PC12 cells, this population of SGs exhibited a significantly higher MSD (GFP-sh2-RNA: $3.79 \pm$ $0.90 \mu \mathrm{m}^{2}$; GFP-sh3-RNA: $3.61 \pm 0.57 \mu \mathrm{m}^{2}$; Fig. 2 E) than in control cells $\left(1.32 \pm 0.52 \mu \mathrm{m}^{2}\right)$ after $12 \mathrm{~s}$ of tracking. As SGs approaching the plasma membrane show much less restricted movement in the absence of myosin VI, we hypothesized that myosin VI was involved in tethering and retention of SGs within this region, thus contributing to the maintenance of SG density in the cortical region of neurosecretory cells.

To evaluate whether reduced SG density near the plasma membrane impacts on neuroexocytosis, we measured stimulated NPY-human placental alkaline phosphatase (hPLAP) release. Although we did not observe any significant effect of myosin VI knockdown after 15-min stimulation, there was a clear reduction in the evoked release after restimulation with fresh high $\mathrm{K}^{+}$for a further $45 \mathrm{~min}$ (Fig. $2 \mathrm{~F}$ and Fig. S2 A). We found that the duration of stimulation was paramount in the detection of the exocytic phenotype. Indeed, long-term TIRF imaging of NPYmCherry-labeled SGs from myosin VI stable knockdown cells (Fig. 2 G) clearly showed that the density of SGs steadily decreased with prolonged stimulation, an effect that was not detected in control cells (Fig. $2 \mathrm{H}$ and Fig. S2 B). Myosin VI knockdown therefore promotes a defect in the recruitment and retention of SGs to the cortical actin network. Collectively, our data demonstrate that by retaining SGs in the cortical actin network, myosin VI plays an important role in the replenishment and maintenance of an active pool of SGs, required to sustain neuroexocytosis.

\section{Myosin VI SI isoform regulates activity-dependent recruitment of SGs to the cortical actin network and exocytosis in PC12 cells}

We confirmed that the myosin VI NI and SI isoforms were present in PC12 cells (Fig. 3 A). To assess the involvement of the different isoforms in neuroexocytosis, PC12 cells coexpressing NPY-hPLAP with either GFP (control), GFP-myosin VI SI full length (GFP-MyoVI-SIfull; Fig. 3 B), or GFP-myosin VI NI full length (GFP-MyoVI-NIfull; Fig. 3 B) were stimulated with high $\mathrm{K}^{+}$, and NPY release was measured. Importantly, these proteins showed comparable expression levels (Fig. 3 C). The release assay showed that GFP-MyoVI-SIfull expression potentiated the evoked release of NPY by $58 \%$ when compared with that of stimulated control cells $(17 \%$ NPY-hPLAP release in control cells vs. 27\% NPY-hPLAP release in GFP-MyoVI-SIfull-expressing cells) in response to the first round of stimulation (15 min; Fig. 3 D). This potentiating effect was maintained after a second round of stimulation (45 min; Fig. 3 D) and was specific for the myosin VI SI isoform, as we did not observe any change in evoked release upon GFP-MyoVI-NIfull expression (Fig. 3 D).

We next performed rescue experiments in myosin VI stable knockdown PC12 cells and evaluated the NPY-hPLAPevoked release upon reexpression of the different isoforms. We found that expression of GFP-MyoVI-SIfull, but not GFPMyoVI-NIfull, was sufficient to rescue stimulated exocytosis (Fig. 3 E), confirming a specific role for myosin VI SI in the maintenance of regulated exocytosis in neurosecretory cells. To elucidate whether the mechanism underpinning this isoform-specific function relied on the ability of myosin VI SI to anchor SGs to the cortical actin network, we used TIRF microscopy to analyze the motility of SGs in myosin VI knockdown cells expressing NPY-mCherry alone (myosin VI knockdown) or after expression of GFP-MyoVI-SIfull or GFP-MyoVI-NIfull (Fig. 4, A and B). Strikingly, the trajectories of SGs associated with GFP-MyoVI-SIfull (GFP-MyoVI-SIfull-positive SGs) were highly confined when compared with those not associated with GFP-MyoVI-SIfull (GFP-MyoVI-SIfullnegative SGs; Fig. 4, A, C, and E; and Video 1) or associated with GFP-MyoVI-NIfull (GFP-MyoVI-NIfull-positive SGs; Fig. 4, B, D, and F; and Video 2). Collectively, these data point toward an anchoring role for myosin VI SI in tethering SGs near the plasma membrane.

We predicted that expression of N-terminal deletion mutants (GFP-MyoVI-tails; Fig. 3 B), lacking the ability to interact with actin (Mermall et al., 1998; Wells et al., 1999; Krendel and Mooseker, 2005), should alter the behavior of SGs at the plasma membrane by acting in a dominant-negative manner. PC12 cells coexpressing NPY-mCherry with either GFP (control), GFP-MyoVI-SIfull, GFP-MyoVI-NIfull, GFP-myosin VI SI tail (GFP-MyoVI-SItail), or GFP-myosin VI NI tail (GFP-MyoVINItail) were imaged by TIRF microscopy (Fig. 5 A). Neither GFP-MyoVI-SIfull nor GFP-MyoVI-NIfull expression affected SG density near the plasma membrane compared with control (Fig. 5 B). In contrast, expression of GFP-MyoVI-SItail, but not GFP-MyoVI-NItail, significantly reduced SG density both before and after stimulation when compared with control cells or cells expressing GFP-MyoVI-SIfull (Fig. 5 B). Consistent with a role for myosin VI in anchoring SGs to the cortical actin network, the average speed of the SGs was significantly increased when either GFP-MyoVI-SItail or GFP-MyoVI-NItail was expressed (Fig. 5 C). These results highlight the importance of the interaction between myosin VI and F-actin in regulating the tethering of SGs to the cortical actin network.

in B before and after $100 \mu \mathrm{M}$ nicotine stimulation. (E) Average MSD of tracked NPY-mCherry-positive SG appearing in the TIRF plane and moving toward the plasma membrane in the conditions shown in B, after nicotine stimulation, over $12 \mathrm{~s}$ of tracking. (F) NPY-hPLAP release was measured as described in Materials and methods using a double-stimulation protocol in control PC12 and cells expressing GFP-sh2-RNA or GFP-sh3-RNA. Released NPY-hPLAP is expressed as a percentage of total ( $n=3$ independent experiments). (G) Western blot using the anti-myosin VI antibody in wild-type (wt) or myosin VI stable knockdown (myosin VI KD) PC12 cells. A black line between the two lanes indicates the removal of intervening lanes from the original image for presentation purposes. (H) Wild-type or myosin VI knockdown PC12 cells expressing NPY-mCherry were imaged by TIRF microscopy for 40 min after a single high $\mathrm{K}^{+}$stimulation. 40 frames per time point were analyzed, and the average SG density was quantified. SG density is expressed relative to the density values before stimulation. Error bars are means $\pm \mathrm{SEM} .{ }^{*}, \mathrm{P}<0.05 ;{ }^{* *}, \mathrm{P}<0.01 ;{ }^{* *}, \mathrm{P}<0.001$. 
Figure 3. Myosin VI SI potentiates evoked exocytosis. (A) RT-PCR analysis of myosin VI isoform expression. $\beta$-Actin primers were used as a control. (B) Cartoons of GFP-tagged myosin $\mathrm{VI}$ constructs. The motor domain (purple) contains the actin- and ATP-binding sites, the reverse gear (761-814 aa, yellow) determines the unique directionality of myosin $\mathrm{VI}$ movement along actin, and the tail domain (orange) in the myosin $\mathrm{VI} \mathrm{SI}(1,262 \mathrm{aa})$, but not the myosin VI NI (1,253 aa), contains a 9-aa insert. GFP-MyoVI-tail constructs lack the motor domain and are unable to interact with F-actin. (C) GFP-MyoVI protein expression in PC12 cells was evaluated by Western blotting using an anti-myosin VI antibody. Arrows indicate GFP-MyoVI-full proteins (175 kD) and GFP-MyoVI-tail proteins (85 kD). (D) NPYhPLAP release was evaluated using a doublestimulation protocol in $\mathrm{PCl} 2$ cells expressing GFP (control), GFP-MyoVI-SIfull, or GFP-MyoVINIfull. Released NPY-hPLAP is expressed as a percentage of total NPY-hPLAP $(n=3)$. (E) NPY. hPLAP release was measured in wild-type (wt) and myosin $\mathrm{VI}$ stable knockdown (KD) PC12 cells overexpressing GFP (control), GFP-MyoVISlfull (+GFP-MyoVI-SIfull), or GFP-MyoVI-NIfull (+GFP-MyoVI-NIfull). Released NPY-hPLAP is expressed as a percentage of wild-type PC12 cells $(n=3)$. Error bars are means \pm SEM. $*, \mathrm{P}<0.05 ; * *, \mathrm{P}<0.01 ; * * *, \mathrm{P}<0.001$.
A

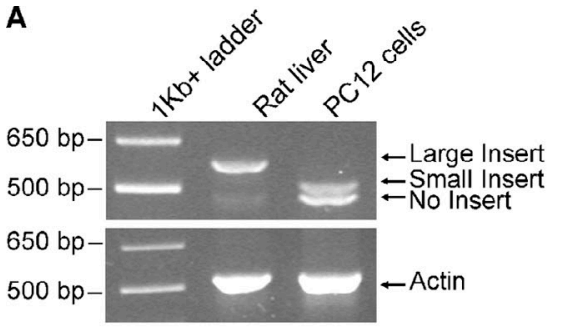

B

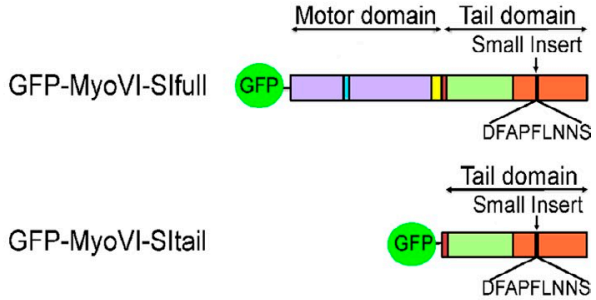

C

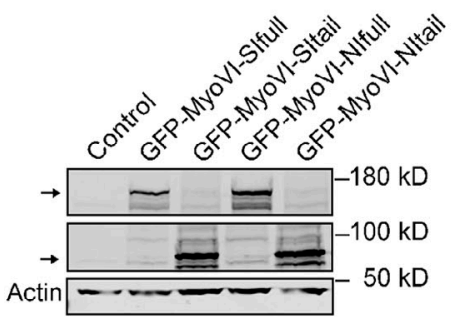

GFP-MyoVI-NIfull

Motor domain Tail domain

GFP-MyoVI-NItail

Tail domain

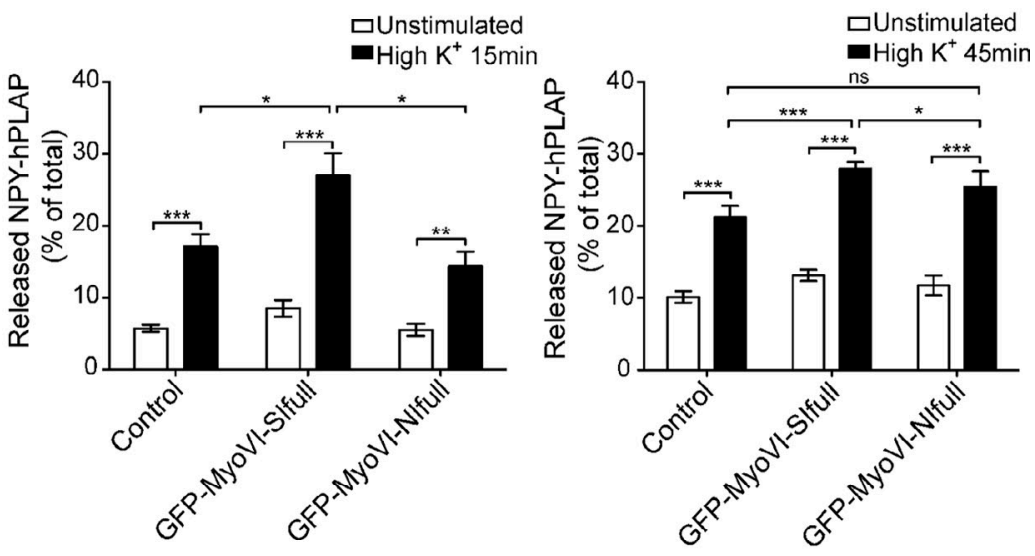

$\mathbf{E}$

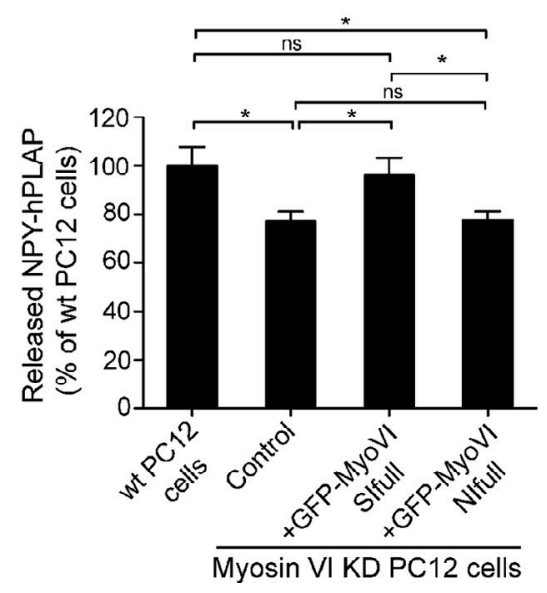

Changes in the type of movement undergone by SGs might also be expected in response to myosin VI overexpression. We used TIRF microscopy to monitor the trajectory of NPY-mCherry-positive SGs and calculate their MSD (Fig. 5, D-F). This analysis included SGs already in the TIRF plane as well as an SG moving toward the plasma membrane, with their trajectories being tracked for longer periods of time than in the previous analysis (Fig. 2 E and Fig. 4) using an automatic algorithm (see Materials and methods). In agreement with the results obtained in myosin VI knockdown cells, overexpression of GFP-MyoVI-SIfull, but not GFP-MyoVINIfull, significantly reduced the MSD (Fig. 5, D and E) and the total displacement of the tracked SGs (Fig. 5 F). Indeed, in cells expressing GFP-MyoVI-SIfull, SG movement was restricted to an area comparable to the known SG diameter (GFP-MyoVI-SIfull $=0.25 \pm 0.04 \mu \mathrm{m}^{2}$; Fig. $5 \mathrm{E}$ ). In contrast, in cells expressing GFP-MyoVI-SItail or GFP-MyoVI-NItail, SGs exhibited a significantly higher MSD than control cells or cells expressing the full-length proteins (Fig. 5, D and E; and Table 2), suggesting that by losing their anchoring points, the 
A
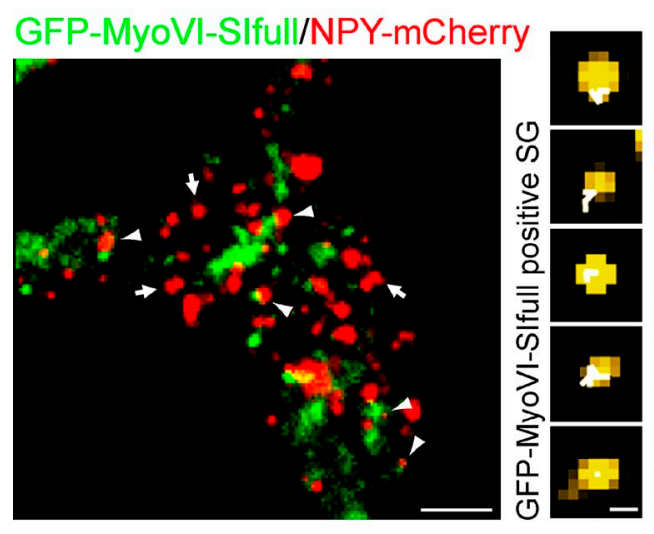

C

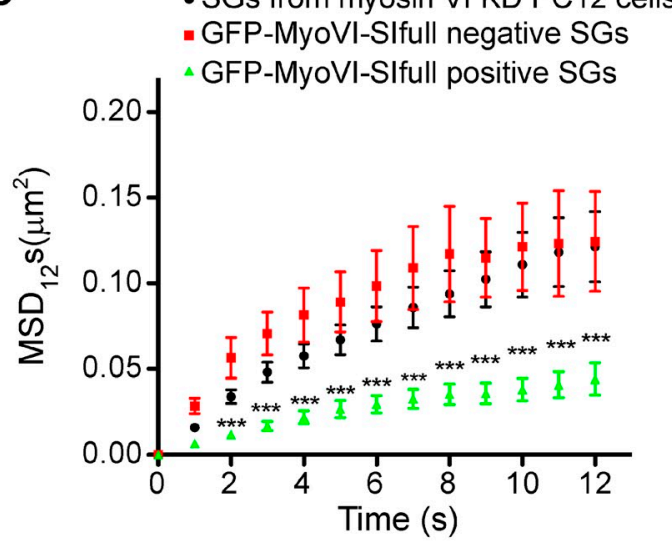

B

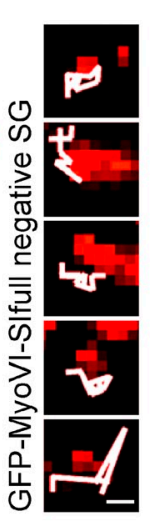

$\mathbf{E}$
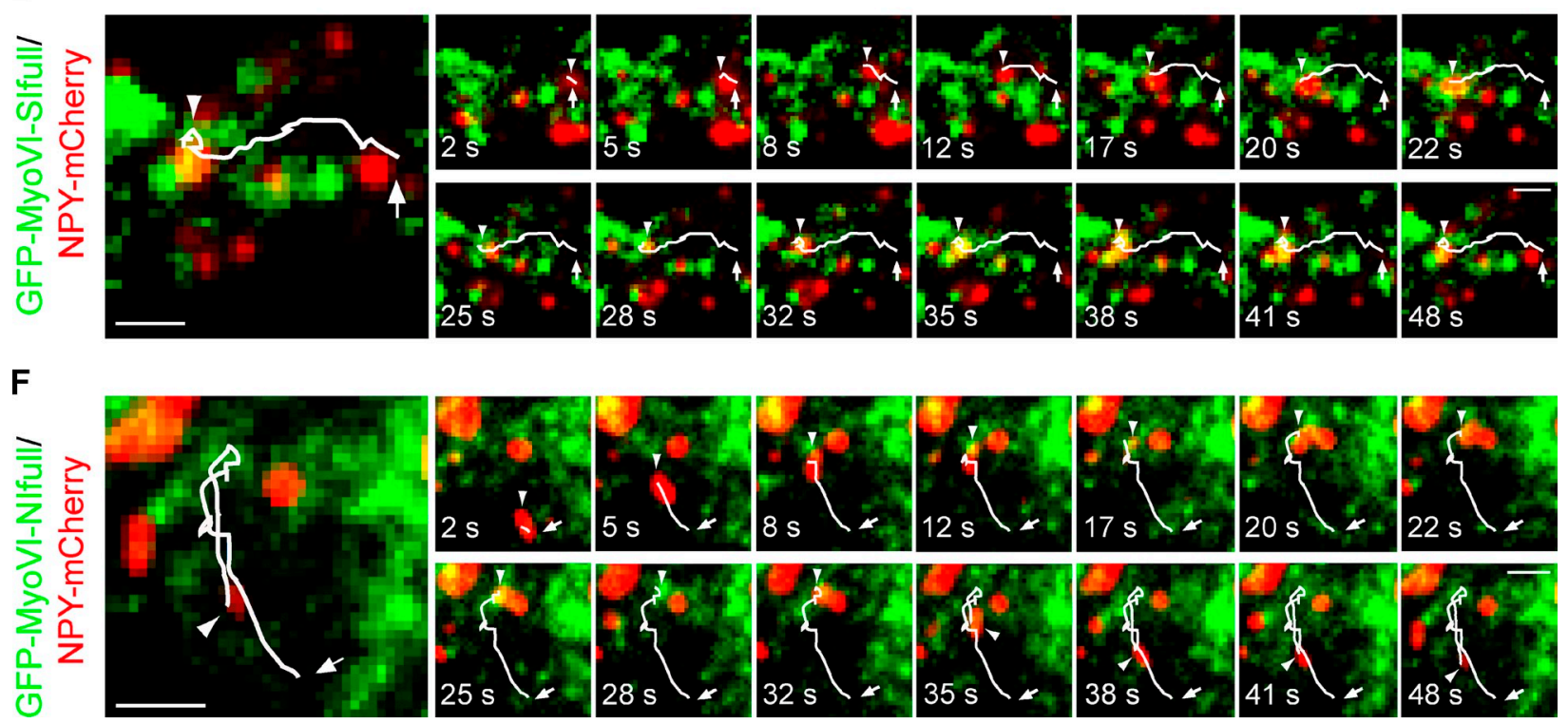

Figure 4. Myosin VI SI mediates the caging of SG to the cortical actin network in myosin VI knockdown cells. (A and B) Myosin VI stable knockdown (KD) PC12 cells coexpressing NPY-mCherry with GFP-MyoVI-SIfull (A) or GFP-MyoVI-NIfull (B) were imaged by TIRF microscopy before and after nicotine stimulation. Videos were acquired at a rate of one frame per second. The insets highlight the trajectories of GFP-MyoVI-positive (arrowheads) and GFP-MyoVI-negative (arrows) SGs during $12 \mathrm{~s}$ after stimulation. (C) Average MSD of NPY-mCherry-positive SGs tracked in untransfected myosin VI stable knockdown cells and in myosin VI stable knockdown cells expressing GFP-MyoVI-SIfull. (D) Average MSD of NPY-mCherry-positive SGs tracked in untransfected myosin VI stable knockdown cells and in myosin VI stable knockdown cells expressing GFP-MyoVI-NIfull. (E) Time-lapse series of a single NPY-mCherry-positive SG appearing in the TIRF plane and becoming highly restricted upon association with GFP-MyoVI-SIfull. The arrow points to the beginning of the trajectory of the SG. The arrowhead shows the end of this trajectory or the position of the SG at each time point. Video 1 shows the complete time series for this panel. (F) Time-lapse series of a single SG labeled with NPY-mCherry appearing in the TIRF plane and becoming GFP-MyoVI-NIfull positive with little effect on its movement. The arrow points to the beginning of the trajectory of the SG. The arrowhead shows the end of this trajectory or the position of the SG at each time point. Video 2 shows the complete time series for this panel. Bars: (A [main images], B [main images], E, and F) $5 \mu \mathrm{m}$; (A [insets] and B [insets]) $1 \mu \mathrm{m}$. Error bars are means \pm SEM. ${ }^{* * *}, \mathrm{P}<0.001$. 

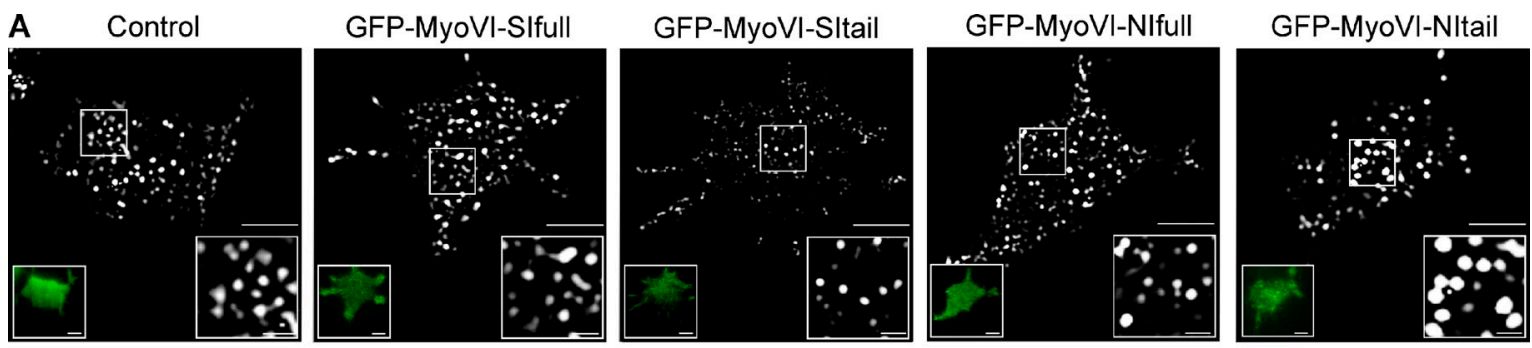

B

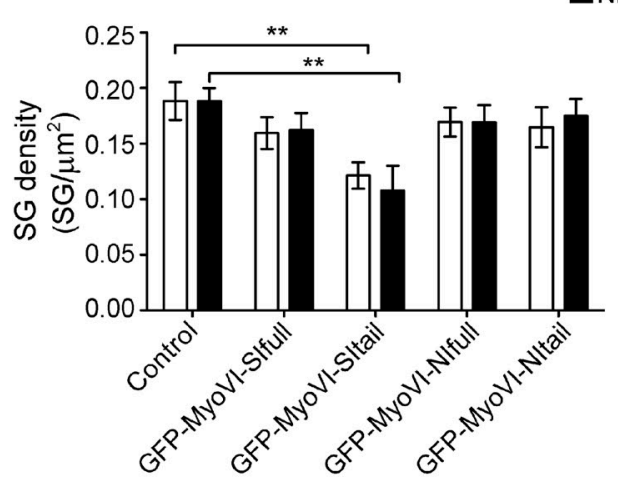

D

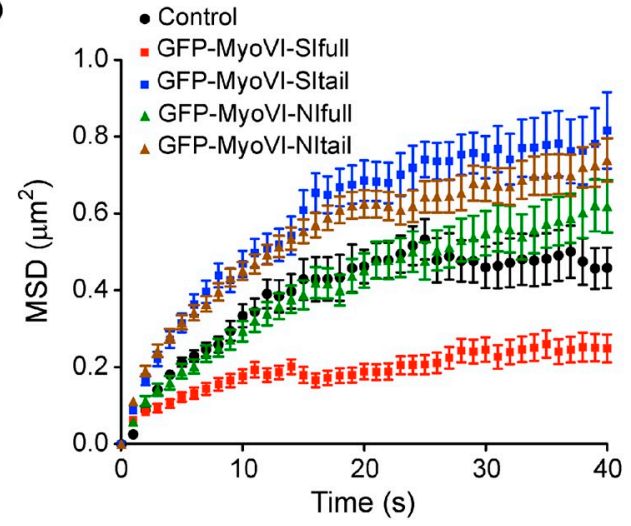

C

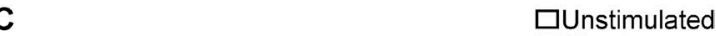

C Nicotine

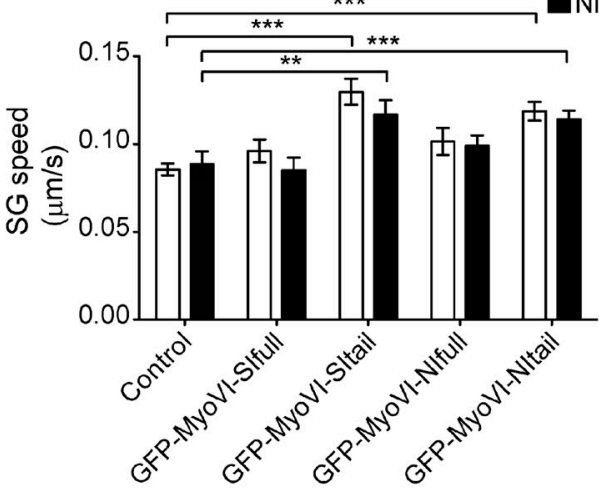

E

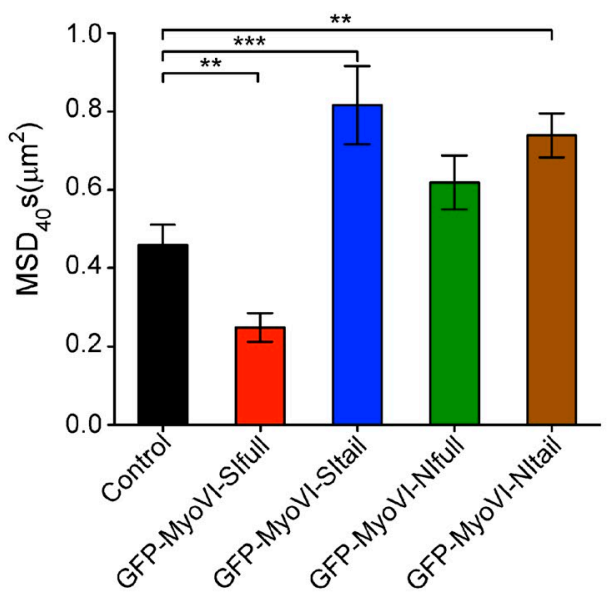

$\mathbf{F}$ GFP-MyoVI-SIfull
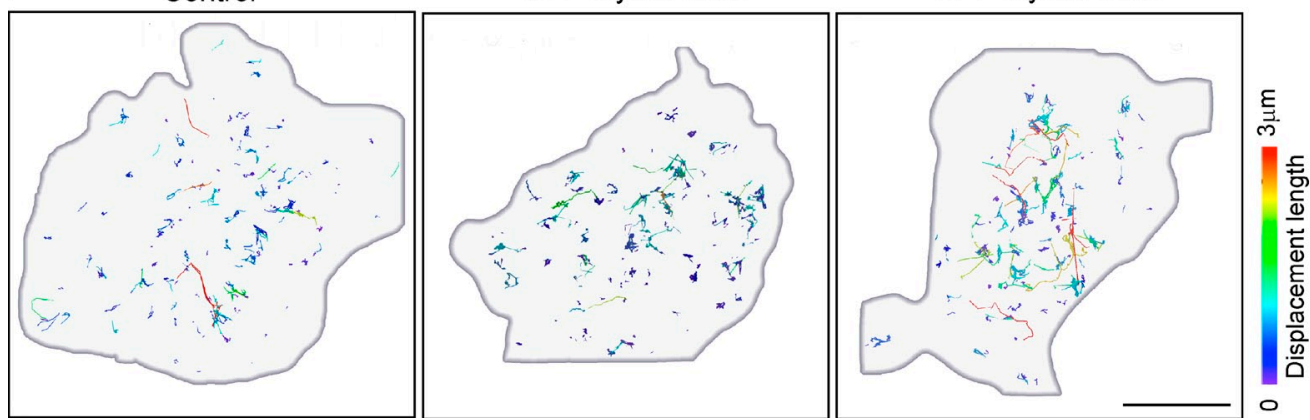

Figure 5. Myosin VI SI regulates SG density and mobility in the cortical region. (A) TIRF images of NPY-mCherry (pseudocolored gray) coexpressed with GFP (control) or with the different GFP-MyoVI proteins in PC1 2 cells. Left insets show GFP or the respective GFP-MyoVI expression. The enlarged images on the right highlight a fixed area for comparison of SG density at the plasma membrane. (B and C) SG density (B) and SG speed (C) in the TIRF plane were quantified in the conditions described in $A$ before and after $100 \mu \mathrm{M}$ nicotine stimulation. (D and E) MSD versus time (D) and average values (E) after $40 \mathrm{~s}$ of tracking of NPY-mCherry-positive SGs shown in A. (F) PC12 cells coexpressing NPY-mCherry with GFP (control), GFP-MyoVI-SIfull, or GFP-MyoVI-Sltail were imaged by TIRF microscopy. NPY-mCherry-positive SGs were tracked, and their lateral movement and displacement length were analyzed. Track displacement length is displayed as a color code. Note the high proportion of short trajectories when the GFP-MyoVI-SIfull was expressed and the very long tracks were detected upon expression of GFP-MyoVI-Sltail. Bars: (A [main images and left insets] and F) 5 um; (A [right insets]) 1 um. Error bars are means \pm SEM. ${ }^{* *}, \mathrm{P}<0.01 ;{ }^{* *}, \mathrm{P}<0.001$. 
Table 2. Myosin VI SI restricts SG mobility in PC12 cells

\begin{tabular}{lcc}
\hline $\begin{array}{l}\text { NPY-mCherry-positive } \\
\text { PC12 cells coexpressing }\end{array}$ & $\boldsymbol{D}$ & Cage area \\
\hline & $\mu \mathrm{m}^{2} / \mathrm{s}$ & $\mu \mathrm{m}^{2}$ \\
Control (GFP) & $0.014 \pm 0.008$ & $0.55 \pm 0.02$ \\
GFP-MyoVI-SIfull & $0.010 \pm 0.001$ & $0.20 \pm 0.01$ \\
GFP-MyoVI-Sltail & $0.020 \pm 0.001$ & $0.81 \pm 0.02$ \\
GFP-MyoVI-NIfull & $0.014 \pm 0.006$ & $0.61 \pm 0.03$ \\
GFP-MyoVI-NItail & $0.022 \pm 0.006$ & $0.68 \pm 0.02$ \\
\hline
\end{tabular}

$D$, diffusion coefficient. Values are expressed as means $\pm 95 \%$ confidence interval.

SGs become more mobile. The MSD plots that we obtained from TIRF analysis were nonlinear (Fig. 5 D) and fitted those generated by caged movement (Steyer and Almers, 1999). The best fit was obtained with a confined diffusion model, which assumes that individual SGs diffuse within a restricted region or cage (Saxton and Jacobson, 1997). This model allowed us to calculate the diffusion coefficient for SG movement and the size of the cage area within which the SGs were confined. Consistent with a myosin VI SI-selective model restricting SG movements, we found that the diffusion coefficient in cells expressing GFP-MyoVI-SIfull was lower than that in control cells or cells expressing GFP-MyoVI-NIfull and that the MSD was significantly reduced (Table 2 ).

Myosin VI SI-positive structures recruit SGs in an activity-dependent manner in PC12 cells

After expression of GFP-MyoVI-SIfull or GFP-MyoVI-NIfull (but not GFP-MyoVI-SItail or GFP-MyoVI-NItail) in PC12 cells, large GFP-positive structures were observed (area $=4.05 \pm$ $0.25 \mu^{2}$ ) in addition to the cytosolic fluorescence (Fig. S3 A). This staining pattern noticeably differed from the small punctate and plasma membrane staining pattern reported in $\mathrm{HeLa}$ and other cells (Buss et al., 1998, 2001; Bond et al., 2011), suggesting that neurosecretory cells have the ability to concentrate a fraction of myosin VI upon overexpression. When expressed in wild-type PC12 cells, the GFP-MyoVI-full-positive structures did not colocalize with any of the tested subcellular compartment markers (Fig. S3 B), and their presence did not affect endocytic or constitutive exocytic events such as transferrin uptake and VSV-G protein delivery to the plasma membrane (Fig. S3, B and C).

To investigate whether these myosin VI-positive structures have the ability to restrict endogenous SGs, PC12 cells expressing GFP-MyoVI-SIfull or GFP-MyoVI-NIfull were immunostained for Synaptotagmin-I (Fig. S4 A). In both cases, a clear colocalization was observed, suggesting that the GFPMyoVI-positive structures were capable of recruiting SGs. Although GFP-MyoVI-SIfull or GFP-MyoVI-NIfull expression did not affect the organization of the cortical actin network (Fig. S3 D), we also investigated whether the GFP-MyoVIpositive structures were able to recruit F-actin. Coexpression of lifeact-mRFP, an F-actin marker (Riedl et al., 2008), with GFPMyoVI-SIfull or GFP-MyoVI-NIfull revealed that actin colocalized with the GFP-MyoVI-positive structures (Fig. S4 C).
Although multiple and smaller GFP-positive structures were observed upon expression of GFP-MyoVI-SItail or GFP-MyoVINItail, these did not colocalize with either Synaptotagmin-I or lifeact-mRFP (Fig. S4, B and D). Using correlative EM, we observed that fluorescent GFP-MyoVI-SIfull structures exhibited a clear concentration of dense-core SGs (Fig. 6 A). The formation of GFP-MyoVI-positive structures and the clustering of SGs around them were completely disrupted by latrunculin A inhibition of actin polymerization (Fig. S4, E-G; Spector et al., 1983). Importantly, GFP-MyoVI full-length expression did not affect microtubule organization (Fig. S4 H), and microtubule depolymerization by nocodazole (Jordan and Wilson, 1998) had no effect on the localization of GFP-MyoVI or the clustering of SG around the GFP-MyoVI-positive structures (Fig. S4, I and J).

We next evaluated whether nicotine stimulation could promote the recruitment of NPY-mCherry-positive SGs to the GFP-MyoVI-positive structures. Time-lapse confocal microscopy revealed a significant increase in NPY-mCherry intensity around the GFP-MyoVI-SIfull-positive structures, but not GFPMyoVI-NIfull structures, in response to stimulation (Fig. 6, $\mathrm{B}$ and $\mathrm{C}$ ). This increase was not observed in cells coexpressing NPY-mCherry with either GFP-MyoVI-SItail or GFP-MyoVINItail, indicating that the recruitment of SGs requires the interaction between myosin VI SI and F-actin (Fig. 6, D and E). Thus, the myosin VI SI isoform has the unique ability to recruit SGs in an F-actin- and activity-dependent manner in PC12 cells. Interestingly, in myosin VI stable knockdown PC12 cells, the occurrence of these large GFP-MyoVI-positive large structures was greatly diminished upon reexpression of GFP-MyoVI-full (Fig. 6 F), with the appearance of small puncta with an average area of $0.20 \pm 0.01 \mu \mathrm{m}^{2}$ that colocalized with Synaptotagmin-I (Fig. $6 \mathrm{G}$ ). The formation of the large structures detected upon GFP-MyoVI-full protein expression in PC12 cells is therefore likely to be driven by elevated levels of myosin VI.

\section{Phosphorylation of myosin VI SI regulates its function in neuroexocytosis}

The SI (Fig. 7 A) contains a potential tyrosine phosphorylation site (Y1114) within a DYD motif (residues 1,113-1,115) not present in the NI isoform. Bioinformatic analysis revealed that this DYD motif is a consensus site for c-Src kinase phosphorylation (Schwartz and Gygi, 2005) of Y1114 (Fig. 7, B and C). Immunoprecipitation experiments were conducted in PC12 cells coexpressing GFP-MyoVI-SIfull or GFP-MyoVI-NIfull with a constitutively active mutant of c-Src kinase, c-SrcY527F-GFP (Fig. 7 D; McLachlan et al., 2007). Tyrosine phosphorylation of GFP-MyoVI, analyzed by Western blotting using an antiphosphotyrosine antibody, revealed that myosin VI SI is indeed preferentially phosphorylated by c-Src when compared with myosin VI NI (Fig. 7, D and E). To determine whether myosin VI SI phosphorylation occurs on Y1114, we generated a DYD deletion mutant of GFP-MyoVI-SIfull (GFP-MyoVI-SIfull $\Delta$ DYD; Fig. 7 C). As predicted, GFP-MyoVI-SIfull $\Delta$ DYD was not phosphorylated after coexpression with c-SrcY527F-GFP. GFPMyoVI-SIfull phosphorylation was also detected after coexpression of wild-type c-Src-mCherry, suggesting that it also occurs 
A

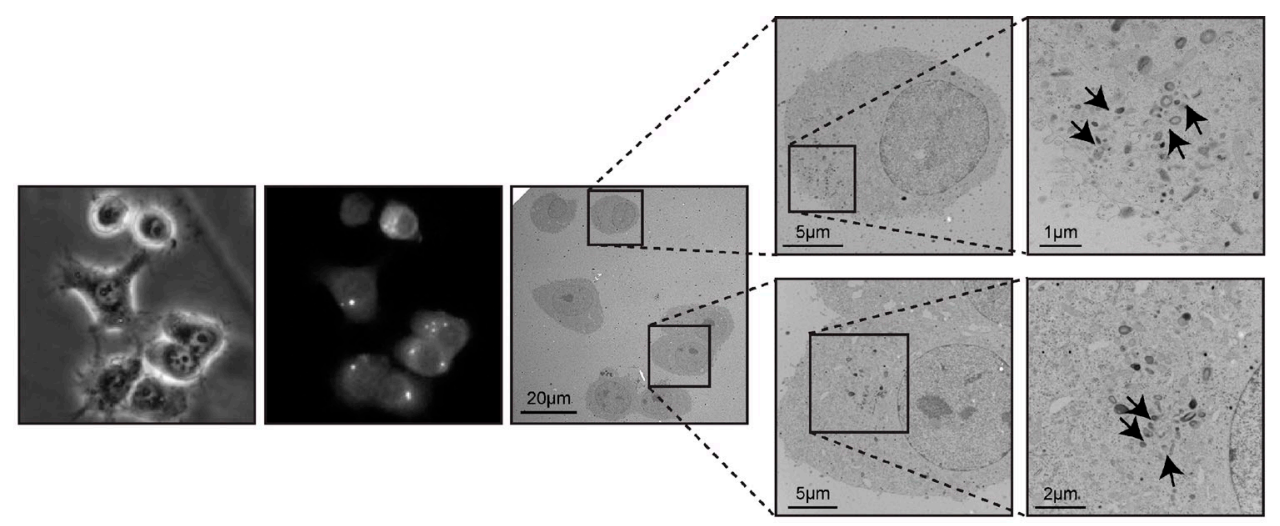

B

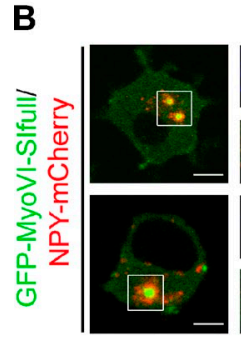

C

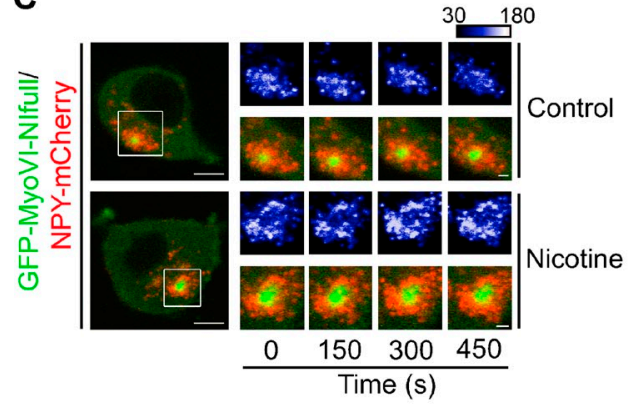

$30 \quad 180$

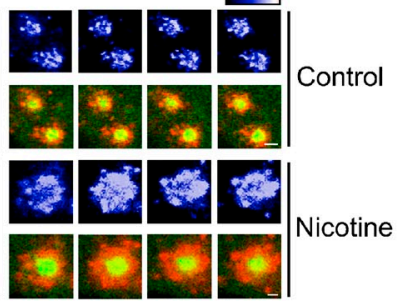

\begin{tabular}{llll}
0 & 150 & 300 & 450 \\
\hline
\end{tabular}

Time (s)
F

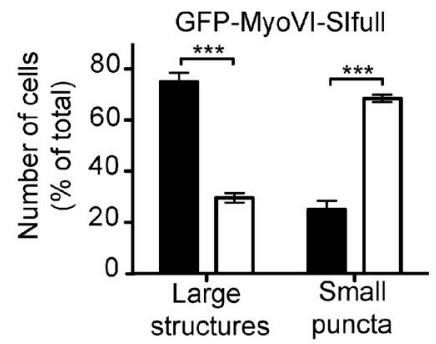

GFP-MyoVI-NIfull

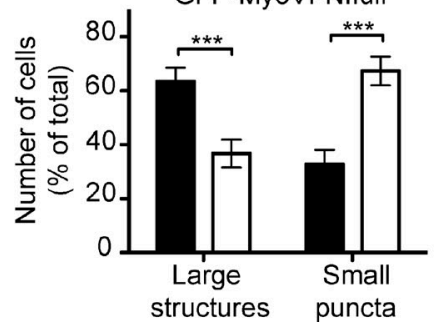

D
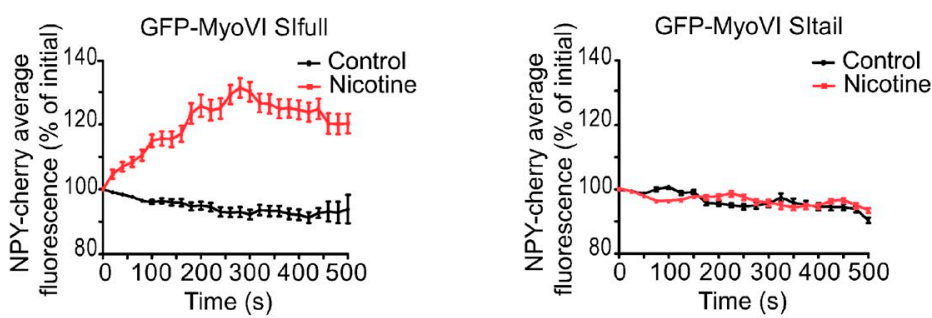

E
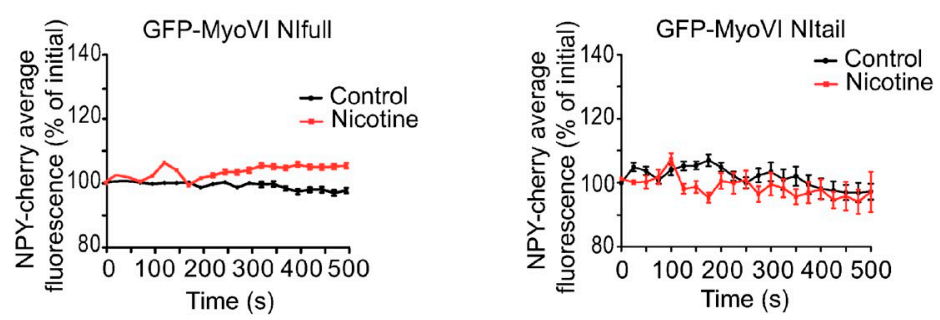

Synaptotagmin-I
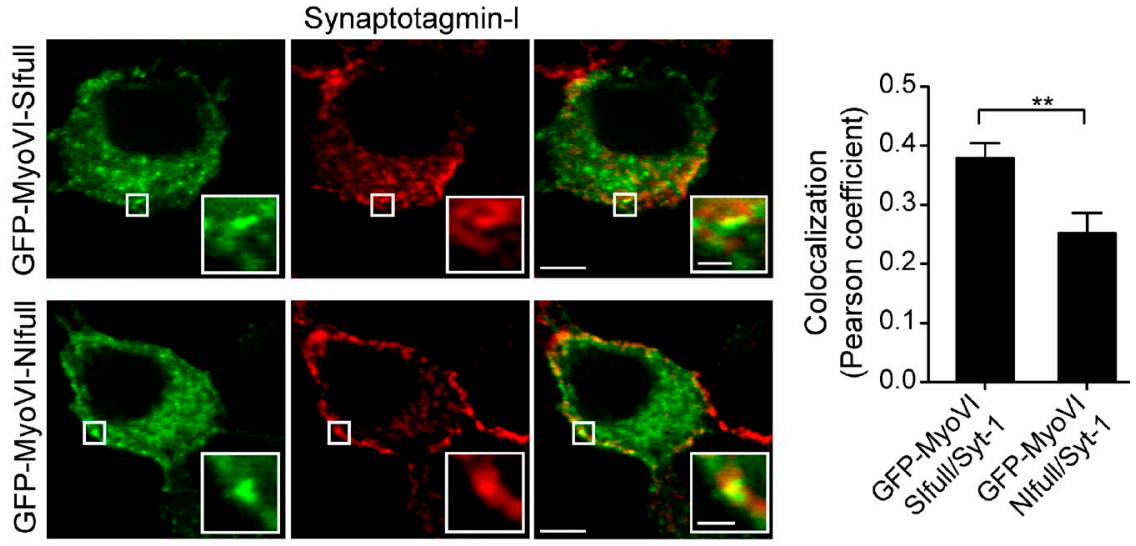

Figure 6. Myosin VI SI recruits SGs in an activity- and F-actin-dependent manner. (A) Bright-field, epifluorescence, and EM images of PC12 cells expressing GFP-MyoVI-SIfull processed for correlative EM. Arrows indicate dense-core SGs clustered in the region of transfected cells where the GFPMyoVI-SIfull-positive structures are located (insets). (B and C) Live-cell confocal images of PC12 cells coexpressing NPY-mCherry with GFP-MyoVI-SIfull (B) or GFP-MyoVI-NIfull (C) before (control) and after $100 \mu \mathrm{M}$ nicotine (nicotine) stimulation. The insets highlight the NPY-mCherry-positive SGs clustered around GFP-MyoVI-positive structures. The NPY-mCherry images are shown as pseudocolor images. A region of interest around a GFP-MyoVI-positive 
under milder levels of c-Src activity (Fig. S5 A). In addition, confocal microscopy showed that these proteins were highly colocalized when expressed in PC12 cells (Fig. S5 B).

To assess the role of c-Src kinase in myosin VI SI activitydependent recruitment of SGs (Fig. 6 B), PC12 cells coexpressing GFP-MyoVI-SIfull and NPY-mCherry were treated with PP2, a selective inhibitor of the Src kinase family (Hanke et al., 1996; Bain et al., 2003) and then analyzed in real time before and after nicotine stimulation. SG recruitment was completely blocked by PP2 treatment (Fig. 8 A), whereas PP3, an inactive analogue of PP2, had no effect, suggesting that c-Src kinase phosphorylation of GFP-MyoVI-SIfull is required to mediate the SG recruitment observed after stimulation. In addition, we observed that SG recruitment was also blocked when NPY-mCherry was coexpressed with the phosphorylation-null mutant GFP-MyoVI-SIfull- $\triangle$ DYD (Fig. 8 B). To test the importance of myosin VI SI phosphorylation in its function as an anchor for SGs, we performed TIRF microscopy on PC12 cells expressing NPY-mCherry either with GFP (control) or GFP-MyoVI-SIfull $\Delta$ DYD (Fig. 8, D and E). At similar levels of expression (Fig. 8 C), deleting the DYD motif from myosin VI SI abolished the spatial restriction of SGs in the cortical region observed after GFP-MyoVI-SIfull expression (Fig. 8, D and E; and Fig. 5, D and E), thereby demonstrating that phosphorylation of the DYD motif is directly responsible for the caging of SGs on the cortical actin network abutting the plasma membrane. Finally, to investigate the role of Y1114 phosphorylation in neuroexocytosis, we measured high $\mathrm{K}^{+}$-stimulated NPY release in wild-type PC12 cells coexpressing NPY-hPLAP with GFP-MyoVI-SIfull or GFP-MyoVI-SIfull $\Delta$ DYD (Fig. 8 F). This revealed that in cells expressing GFP-MyoVI-SIfull $\Delta$ DYD, NPY release was comparable to that observed in control cells expressing GFP in both the first and second rounds of stimulation (15 and $45 \mathrm{~min}$ ), confirming that the potentiating effect observed upon GFP-MyoVI-SIfull expression was abolished by deleting the DYD motif (Fig. 8 F). A similar effect was seen when cells coexpressing NPY-hPLAP and GFP-MyoVI-SIfull were treated with PP2 (Fig. S5 C). More importantly, expression of GFPMyoVI-SIfull $\triangle D Y D$ failed to rescue evoked release when overexpressed in myosin VI stable knockdown PC12 cells (Fig. 8 G). Together, these results demonstrate that phosphorylation of myosin VI SI in the DYD motif by a Src kinase family member, probably c-Src kinase, is required to regulate myosin VI SI isoform function in regulated exocytosis.

\section{Discussion}

In neurosecretory cells, the cortical actin network has a key role in neuroexocytosis. In resting conditions, it plays a passive role by acting as a diffusion barrier, allowing the recruitment and restriction of SGs to the actin cytoskeleton beneath the plasma membrane (Nakata and Hirokawa, 1992; Trifaró and Vitale, 1993; Steyer and Almers, 1999; Oheim and Stühmer, 2000; Toonen et al., 2006). However, upon stimulation, this barrier loosens in response to $\mathrm{Ca}^{2+}$-mediated activation of proteins such as scinderins (Rodriguez Del Castillo et al., 1990; Vitale et al., 1991; Lejen et al., 2002). The cortical actin network then plays a more active role by providing de novo actin tracks for granule movement when actin polymerization is induced by Rho and a rise in phosphatidylinositol(4,5)bisphosphate levels (Gasman et al., 2004; Wen et al., 2011).

Although considerable effort has been devoted to understanding the molecular events underlying neuroexocytosis, the complex mechanisms that allow SG recruitment and retention at the level of the cortical actin network, and their subsequent transport to the plasma membrane, remain to be fully elucidated. To gain insight into these mechanisms and to identify cytosolic proteins that regulate the recruitment of SGs to F-actin in a $\mathrm{Ca}^{2+}$ dependent manner, we used purified SGs to pull down proteins from purified cytosol in the presence of $\mathrm{Ca}^{2+}$ and identified them by MS. Among the pulled down proteins were those known to interact with SGs in a $\mathrm{Ca}^{2+}$-dependent manner, such as annexin-2 (Sarafian et al., 1991; Chasserot-Golaz et al., 2005), proteins involved in endocytic and exocytic trafficking pathways, such as heat shock protein-70 kD (Rothman, 1989; Jiang et al., 2000), and cytoskeleton components, including tubulin, actin, and myosin VI. Myosin VI was of interest as it had previously been described to have an anchoring function that allows the attachment of membrane compartments to the actin cytoskeleton (Self et al., 1999; Buss and Kendrick-Jones, 2008). Although it was recently found to colocalize with an SG marker in PC12 cells, its role in regulated secretion remains a matter of debate (Majewski et al., 2011). Here, we provide the first demonstration that myosin VI interacts with SGs in a $\mathrm{Ca}^{2+}$-dependent manner and drives the tethering and retention of SGs to F-actin in the cortical actin network. The regulation of the anchoring property of myosin VI by Src kinase phosphorylation highlights the importance of posttranslational modifications in controlling myosin VI activity and its functional link with signal transduction pathways.

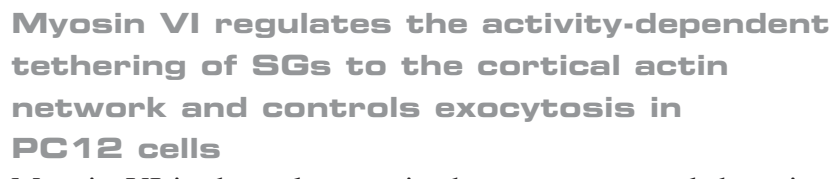
Myosin VI is the only myosin that moves toward the minus end of actin filaments (Wells et al., 1999) and, in association with specific binding partners, functions in endocytosis, cell

structure was used for quantification of NPY-mCherry fluorescence (right graphs) in the conditions described in B and C. (D and E) Quantification of NPYmCherry fluorescence around GFP-MyoVI-Sltail (D)- or GFP-MyoVI-Nltail (E)-positive structures before (control, black) and after $100 \mu M$ nicotine stimulation (nicotine, red). Average NPY-mCherry fluorescence is expressed as a percentage of initial fluorescence. (F) GFP-MyoVI-SIfull and GFP-MyoVI-NIfull were expressed in wild-type (wt) or myosin VI stable knockdown (myosin VI KD) PC12 cells. After fixation, cells were imaged by confocal microscopy, and the number of cells harboring large GFP-MyoVI-positive structures (large structures) or small punctate cytosolic distribution (small puncta) were counted and expressed as a percentage of the total number of transfected cells ( $n=3$ independent experiments). (G, left) Confocal images of myosin VI stable knockdown PC1 2 cells expressing GFP-MyoVI-SIfull or GFP-MyoVI-NIfull immunolabeled with Synaptotagmin-l (red). The enlarged images show the association between expressed GFP-MyoVI and Synaptotagmin-I (Syt-I). (right) Analysis of the colocalization between Synaptotagmin-I and the different GFP-MyoVI. Bars: (B, C, and $G$ [main images]) $5 \mu \mathrm{m} ;(B, C$, and $G$ [insets]) $1 \mu \mathrm{m}$. Error bars are means $\pm S E M . * *, P<0.01 ; * * *, P<0.001$. 
A

Myosin VI SI
Myosin VI NI
Myosin VI SI
Myosin VI NI
Myosin VI SI
Myosin VI NI

1021 AELISDEAQADLALRRGPAVLATKAAAGTKKYDLSKWKYAELRDTINTSCDIELLAACRE 1080 1021 AELISDEAQADLALRRGPAVLATKAAAGTKKYDLSKWKYAELRDTINTSCDIELLAACRE 1080

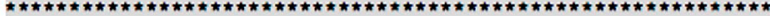

1081 EFHRRLKVYHAWKSKNKKRNTETEQRAPKSVTDYDFAPFLNNS QQQNPAAQIPARQREIE 1140 1081 EFHRRLKVYHAWKSKNKKRNTETEQRAPKSVTDY--------PQQNPAAQIPARQREIE 1131

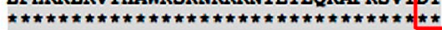

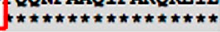

1141 MIROORFFRIPFIRPADOYKDPOSKKKGWWYAHFDGPWIAROMELHPDKPPILLVAGKDD 1200 1132 MNRQQRFFRIPFIRPADQYKDPQSKKKGWWYAHFDGPWIARQMELHPDKPPILLVAGKDD 1191
B

Myosin VI small insert

Phosphotyrosine predictions
Myosin VI no insert

Phosphotyrosine predictions

\begin{tabular}{|c|c|c|c|c|c|c|c|}
\hline \multirow{4}{*}{$\begin{array}{l}\frac{\text { Position }}{1089} \\
1114\end{array}$} & \multirow[b]{2}{*}{ Context } & & & \\
\hline & & Score & Prediction & Position & Context & Score & Predi \\
\hline & RLKVYHAWK & 0.014 & - & 1089 & RLKVYHAWK & 0.014 & \\
\hline & SVTDYDFAP & 0.912 & ${ }^{*} Y^{*}$ & 1114 & SVTDYPQQN & 0.726 & \\
\hline \multirow[t]{5}{*}{1159} & PADQYKDPQ & 0.977 & ${ }^{*} Y^{*}$ & 1159 & PADQYKDPQ & 0.977 & \\
\hline & \multicolumn{2}{|c|}{$\begin{array}{c}\text { Kinase prediction } \\
\text { Kinase }\end{array}$} & \multicolumn{2}{|l|}{ Score } & \multicolumn{2}{|c|}{ Kinase prediction } & Score \\
\hline & $\overline{\mathrm{Y}-1114}$ & & $\overline{0.37}$ & & & & \\
\hline & $Y-1114$ & & 0.51 & & $Y-1114$ & & 0.57 \\
\hline & Y-1114 & & 0.48 & & Y-1114 & & 0.45 \\
\hline
\end{tabular}

C

$\underset{\text { Motor domain }}{\stackrel{\text { Tail domain }}{\longrightarrow}} \underset{\text { Small Insert }}{\stackrel{\text { a }}{\longrightarrow}}$

GFP-MyoVI-SIfull

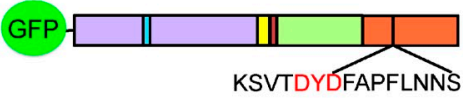

GFP-MyoVI-SIfullDDYD GFP

D

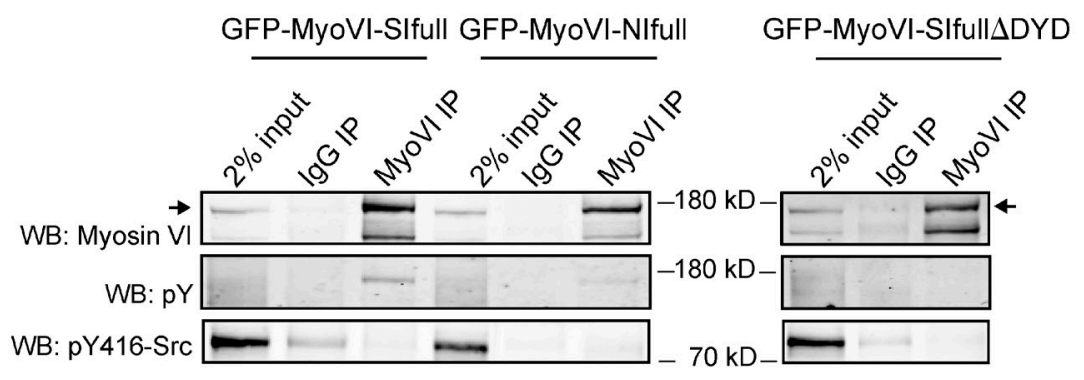

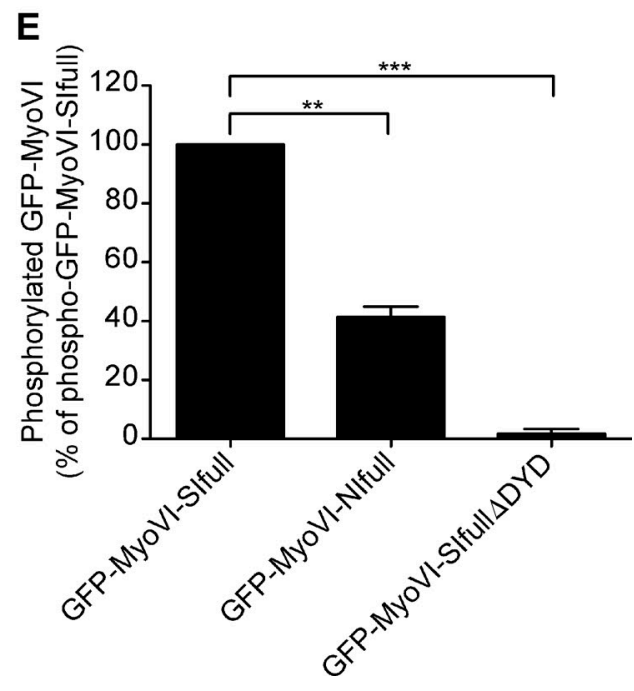

Figure 7. Myosin VI SI isoform is phosphorylated by c-Src kinase. (A) Alignment of the tail domain sequences of the myosin $\mathrm{VI} \mathrm{SI}$ and myosin $\mathrm{VI} \mathrm{NI}$ isoforms. The DYD motif comprises part of the SI (9 aa) and an adjacent aspartate (D1113) and tyrosine (Y1114) residue (red, aa 1,113-1, 123). (B, top) Prediction of tyrosine phosphorylation sites in the region 1,100-1,150 aa in the myosin VI SI (left) and myosin VI NI (right) isoforms. Highlighted in red is the Y1114 residue that displays a higher phosphorylation score in myosin VI SI than in myosin VI NI (0.912 vs. 0.726). (bottom) Prediction of kinase-specific phosphorylation sites in myosin VI SI (left) and myosin VI NI (right) isoforms. Highlighted in red is the Y1 114 residue predicted to be phosphorylated by c-Src protein kinase in myosin VI SI. (C) Schematic comparison between GFP-MyoVI-SIfull and GFP-MyoVI-SIfullDDYD (see Fig. 3 for colored references) with the deleted DYD motif (aa 1,1 13-1,1 15) in red. (D) Immunoprecipitation of GFP-MyoVI from cells coexpressing GFP-MyoVISIfull, GFP-MyoVI-NIfull, or GFP-MyoVI-SIfull $\triangle$ DYD with c-SrcY527F-GFP. (top) Western blotting using an anti-myosin VI antibody. Arrows indicate GFP-MyoVI. (middle) Phosphorylation of immunoprecipitated GFP-MyoVI detected by Western blotting using antiphosphotyrosine (pY) antibody. (bottom) c-SrcY527F-GFP expression detected by Western blotting using a specific antiphospho-Src antibody (pY416-Src, 84 kD). (E) Quantification of phosphorylated GFP-MyoVI expressed as a percentage of phosphorylated GFP-MyoVI-SIfull $(n=3)$. IP, immunoprecipitation; WB, Western blot. Error bars are means \pm SEM. ${ }^{* *}, \mathrm{P}<0.01 ;{ }^{* * *}, \mathrm{P}<0.001$. 
migration, and constitutive protein secretion (Buss et al., 2001; Aschenbrenner et al., 2003; Roberts et al., 2004; Au et al., 2007; Bond et al., 2011). Here, we demonstrate that in neurosecretory cells, myosin VI has a novel role in actively recruiting SGs to the cortical actin network. When myosin VI expression is knocked down, the pool of SGs retained close to the cell surface is reduced. Although the average speed of the SGs is not affected in this condition, the pool of SGs progressing toward the plasma membrane displays a less restricted movement, suggesting the loss of an anchoring point to the cortical region mediated by myosin VI. Importantly, the sustainability of SG exocytosis is impaired after myosin VI knockdown. Our results indicate that myosin VI does not affect the early stages of stimulated secretion, but by maintaining an active pool of SGs below the plasma membrane and actively recruiting them to the cortical actin network, it plays a critical role in sustaining neuroexocytosis. Further evidence that the interaction between myosin VI and F-actin is required for the cortical tethering and retention of SGs was provided by the observation that expression of myosin VI tail, a truncated protein that is unable to interact with F-actin, dramatically reduced the pool of SGs near the plasma membrane and increased the average speed of the SGs.

Myosin Va has also been implicated in neurosecretion. It is present on SGs (Lejen et al., 2002; Varadi et al., 2005) and is involved in SG movement to the cell surface (Prekeris and Terrian, 1997; Rudolf et al., 2003; Eichler et al., 2006; Desnos et al., 2007; Kögel et al., 2010). Therefore, myosin Va and VI may have synergistic roles, with myosin VI acting in the recruitment and retention of SGs to the cortical actin network and myosin $\mathrm{Va}$ involved in the active transport of SGs toward the plasma membrane. Interestingly, a recent in vitro study using single myosin Va and myosin VI molecules linked to the same cargo describes how physical communication between these molecular motors could modulate cargo delivery (Ali et al., 2011).

\section{Myosin VI SI isoform controls the}

recruitment of SGs to F-actin and

regulated exocytosis in PC12 cells

Although large insert and NI isoforms of myosin VI have been reported to be involved in cargo sorting and clathrin-mediated endocytosis (Au et al., 2007; Puri, 2009), the function of the SI isoform was unknown. We confirmed that PC12 cells endogenously express both the myosin VI SI and myosin VI NI isoforms (Majewski et al., 2010). Although the expression of truncated tail mutants of both isoforms affected SG speed and mobility near the plasma membrane, only the myosin VI SI tail mutant reduced SG density, suggesting that the tethering and retention of SGs to the cortical region is predominantly mediated by the myosin VI SI isoform. We also observed that additional SGs were recruited in an activity-dependent manner around myosin VI SI-positive structures alone and that although expression of this isoform did not affect the net density of SG near the plasma membrane, it did potentiate their evoked release. Consistent with a specific role of the myosin VI SI in neuroexocytosis, we found that this isoform, but not myosin VI NI, was able to restore the defective exocytic phenotype detected in myosin VI knockdown cells by mediating the efficient caging and retention of SGs in the cortical actin network. Thus, our data provide the first demonstration that the myosin VI SI isoform acts as an anchor molecule and is responsible for the activity-dependent recruitment of SGs to F-actin in PC12 cells, a function that is required for the maintenance of an active and competent pool of SGs needed to sustain neuroexocytosis.

\section{Phosphorylation as a positive regulatory mechanism for the role of myosin VI SI \\ in neuroexocytosis}

The activity of several kinases is known to modulate neurotransmitter release pre- and postsynaptically (Gurd, 1997; Turner et al., 1999). c-Src kinase is highly expressed in neurosecretory cells and neurons and is associated with synaptic vesicles (Onofri et al., 1997; Ingley, 2008). Although c-Src kinase activity is up-regulated by $\mathrm{Ca}^{2+}$, its functions in regulated exocytosis remain a matter of debate (Pang et al., 1988; Linstedt et al., 1992; Rusanescu et al., 1995). In neuronal cells, c-Src has been variously reported to have an inhibitory effect mediated by its substrate synapsin-1 (Messa et al., 2010) as well as a stimulatory role in promoting glutamate release (Wang, 2003; Shyu et al., 2005). In PC12 cells, treatment with $20 \mu \mathrm{m}$ PP2 increased catecholamine release after high $\mathrm{K}^{+}$stimulation, an action attributed to a general disturbance of the actin cytoskeleton, again suggesting an inhibitory role (Ohnishi et al., 2001). Here, we demonstrate that phosphorylation of myosin VI SI on a predicted c-Src kinase consensus site is necessary for the function of myosin VI SI in sustaining SG fusion, pointing to a positive role for c-Src kinase in neuroexocytosis. Although this effect was also observed when the Src kinase inhibitor PP2 was used, PP2 alone did not affect release in PC12 cells during the first 15 min of stimulation, as would be expected. Although the reason for this is currently unknown, it could reflect competing known functions of c-Src kinase in the initial stages of neuroexocytosis. However, possible confounding effects of PP2 on other kinases cannot be ruled out at this time. Future studies directly targeting identification of the signaling pathway regulating myosin VI SI function will be needed to fully address this aspect of neurosecretion. In summary, our work describes a novel role for the myosin VI SI isoform in the regulation of the activitydependent tethering of SGs to the cortical actin network in neurosecretory cells, a key process that is potentially regulated by c-Src kinase phosphorylation.

\section{Materials and methods}

\section{Plasmids}

The GFP-MyoVI plasmids (GFP-MyoVI-SIfull, GFP-MyoVI-Sltail, GFP-MyoVINIfull, and GFP-MyoVI-Nltail) have been described previously (Buss et al., 2001; Au et al., 2007). In brief, the human full-length myosin VI cDNA of the different myosin VI isoforms (UniProt accession no. Q9UM54-2 [SI, 1-1,262 aa] and Q9UM54-5 [NI, 1-1,253 aa]) or the restriction fragments covering their predicted tail domains $(840-1,262$ or 1,253 aa) were cloned into the mammalian expression vector pEGFP-C3 (Takara Bio Inc.) so that they were expressed at the $C$ terminus of EGFP (Fig. 3 B). Lifeact-mRFPruby (Lifeact-mRFP) was provided by R. Wedlich-Soldner (Max Planck Institute of Biochemistry, Martinsried, Germany; Riedl et al., 2008), pCMV-NPY-hPLAP was provided by S. Sugita (University of Toronto and University Health Network, Toronto, Ontario, Canada), c-Src-mCherry and 
A
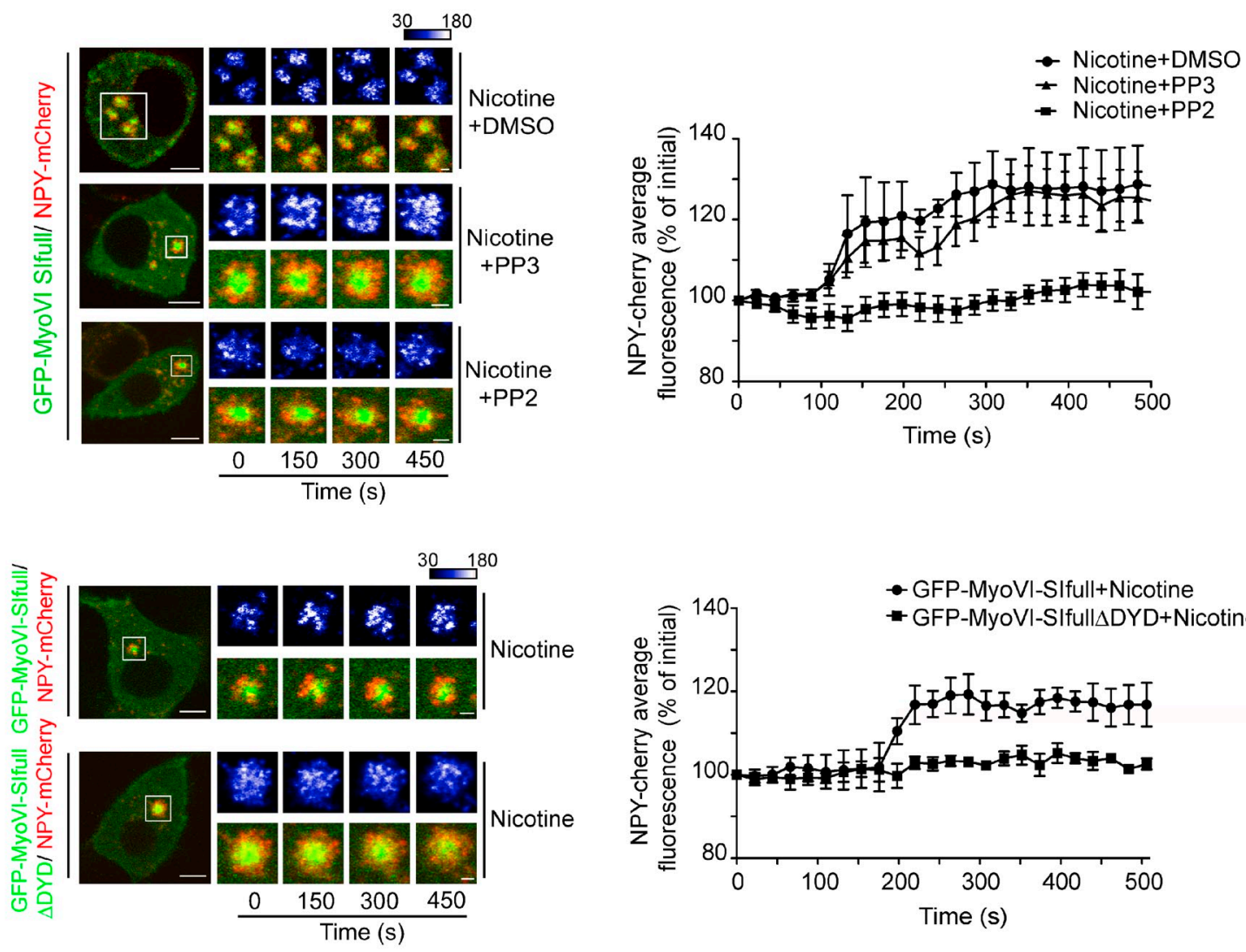

C

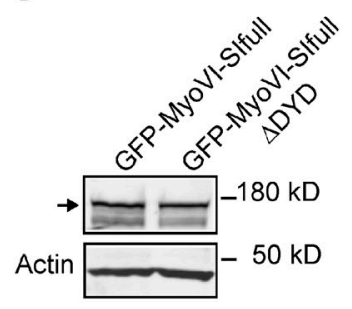

D $\left.{ }^{1.0}\right] \cdot$ Control

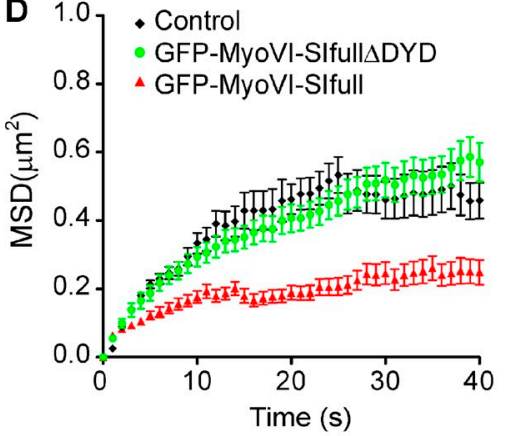

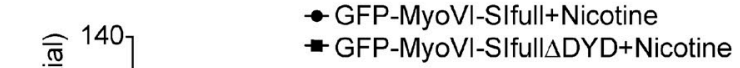

- GFP-MyoVI-SIfull $\triangle \mathrm{DYD}+$ Nicotine
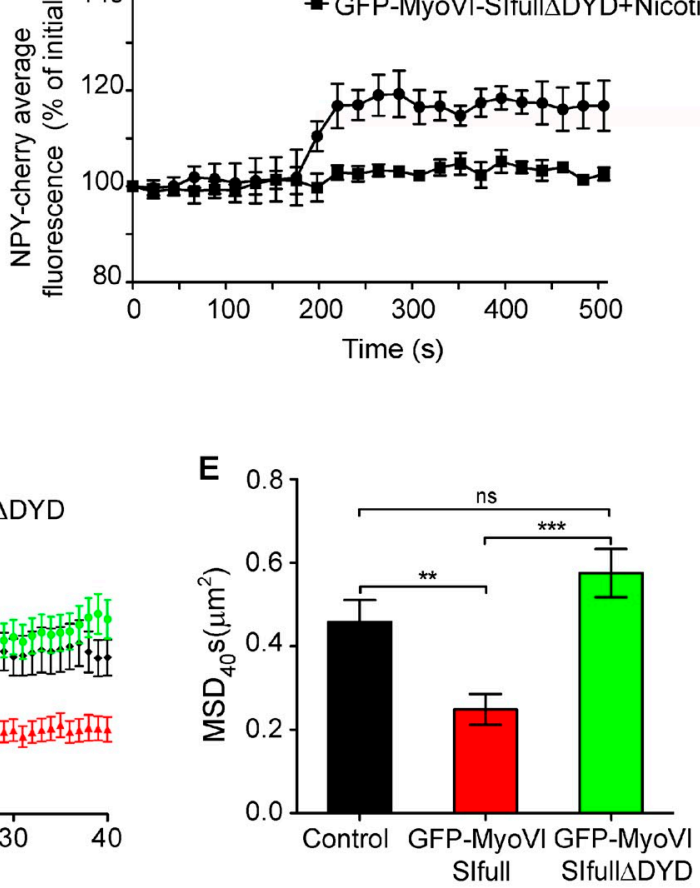

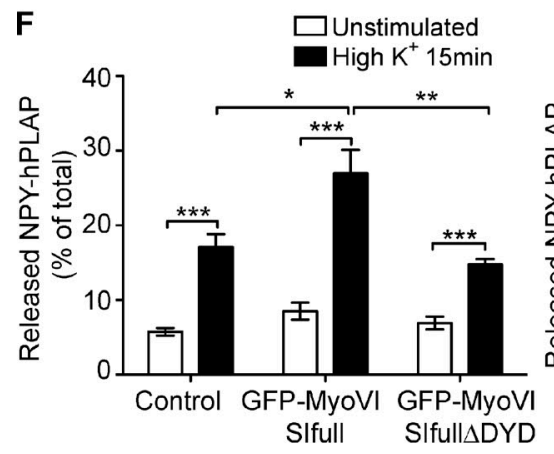

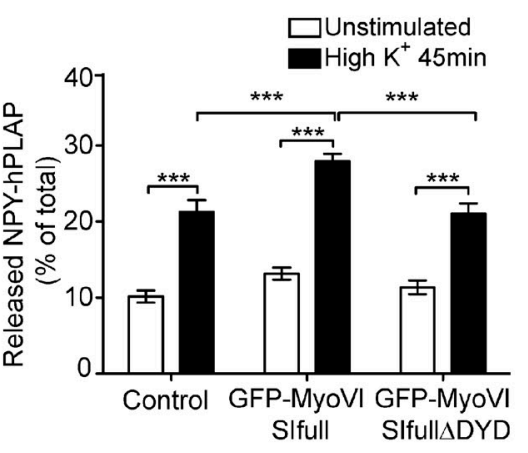

G

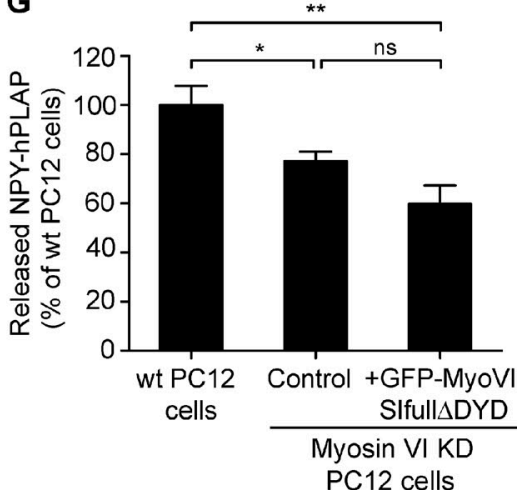

Figure 8. The function of myosin VI SI in neuroexocytosis is regulated by c-Src kinase phosphorylation. (A, left) PC12 cells coexpressing GFP-MyoVI-Slfull and NPY-mCherry pretreated with DMSO, PP3, or PP2 for $40 \mathrm{~min}$ at $37^{\circ} \mathrm{C}$ and imaged after $100 \mu \mathrm{M}$ nicotine stimulation in the presence of DMSO (nicotine + DMSO), PP3 (nicotine + PP3), or PP2 (nicotine + PP2). (right) Quantification of NPY-mCherry fluorescence around GFP-MyoVl-positive structures in the conditions shown in the left images. The NPY-mCherry images are shown as pseudocolor images. (B, left) PC12 cells coexpressing NPY-mCherry with GFP-MyoVI-Slfull or GFP-MyoVI-SIfull $\triangle \mathrm{DYD}$ after $100 \mu \mathrm{M}$ nicotine (nicotine) stimulation. (right) Quantification of NPY-mCherry fluorescence around GFP-MyoVI-positive structures 
c-SrcY527F-GFP were provided by A. Yap (Institute for Molecular Bioscience, University of Queensland, Queensland, Australia; McLachlan and Yap, 2011 ), and VSV-G was provided by J.L. Daniotti (Universidad Nacional de Córdoba, Ciudad Universitaria, X5000 HUA Córdoba, Argentina; Keller et al., 2001). pEGFP-C3 was obtained from Takara Bio Inc. The GFPMyoVI-SIfull DYD motif deletion $(1,113-1,115 \mathrm{aa})$ was generated by sitedirected mutagenesis using the site-directed mutagenesis kit (QuikChange Lightning; Agilent Technologies) and mutational primers 5'-CCAAAGTCTGTTACTTTTGCACCATTTTTG-3' and 5'-CAAAAATGGTGCAAAAGTAACAGACTTGG-3'. pCMV-NPY-mCherry (NPY-mCherry) was generated from pCMV-NPY-emerald GFP provided by S. Sugita. In brief, mCherry was amplified from pmCherry-Cl (Takara Bio Inc.) by PCR using the following primers: forward, 5'-ATCGATAAGCTCATGGTGGCAAGGGCGAG-3'; and reverse, 5'-CAAGTAAAACCTCTACAAATGTGGTATGGC-3'. Then, it was subcloned into PCMV-NPY-emerald GFP using Clal and BamHI, replacing emerald GFP. All constructs were sequenced in the Australian Genome Research Facility at the University of Queensland.

\section{Cell culture and DNA transfection}

$\mathrm{PC} 12$ cells were maintained at $37^{\circ} \mathrm{C}, 5 \% \mathrm{CO}_{2}$ in DMEM supplemented with $5 \%$ Serum Supreme (Lonza), $5 \%$ heat-inactivated horse serum (Gibco; Invitrogen), and $0.5 \%$ GlutaMAX (Gibco; Invitrogen). Cells were transfected with a $1-2.5-\mu g / 35-\mathrm{mm}$ dish of the indicated plasmid using the reagent (Lipofectamine LTX; Invitrogen) according to the manufacturer's instructions. After $24 \mathrm{~h}$, transfected cells were replated onto poly-D-lysine-coated glass-bottomed culture dishes (MatTek Corporation) or coverslips and then processed for live-cell imaging or immunocytochemistry experiments $72 \mathrm{~h}$ after transfection.

\section{Antibodies}

Mouse anti-Synaptobrevin/VAMP2 (1:400), mouse anti-Synaptotagmin-1 clone 41.1 (1:500-1,000), and mouse anti-SNAP25 $(1: 1,000)$ were obtained from Synaptic Systems, mouse anti-EEA 1 (1:400) and mouse antiGM130 $(1: 1,000)$ were obtained from BD, monoclonal rabbit anti-Rab5 (1:500) and rabbit antiphosphotyrosine $416 \mathrm{Src}$ (pY416-Src; 1:500) were purchased from Cell Signaling Technology, mouse anti- $\beta$-actin clone AC-74 $(1: 20,000)$ was purchased from Sigma-Aldrich, and mouse antiphosphotyrosine clone 4G10 (1:500) was obtained from EMD Millipore. Rabbit anti-Syntaxin-6 (1:800) was a giff from D. James (Garvan Institute, Sydney, Australia), mouse anti-protein disulfide isomerase (1:600) was a gift from J. Stow (Institute for Molecular Bioscience, University of Queensland, Queensland, Australia), and rabbit anti-myosin VI antibody (1:500; Fig. 1 C) was provided by A. Yap. For immunocytochemistry, protein expression analyses, and immunoprecipitation experiments, a rabbit polyclonal anti-myosin $\mathrm{VI}$ antibody raised against aa 920-1,034, located in the tail domain of this protein (Buss et al., 1998), was used $(1: 1,000)$. $1 \mu \mathrm{g}$ rabbit lgG (Sigma-Aldrich) was used as a control for immunoprecipitation experiments. The secondary antibodies goat anti-mouse Alexa Fluor 546 and goat anti-rabbit Alexa Fluor 488 (1:400; Molecular Probes; Invitrogen) were used for immunocytochemistry. Anti-mouse (IRDye 680 or 800 ) and anti-rabbit (IRDye 680 or 800 ) infrared antibodies were used for Western blotting (1:25,000; LI-COR Biosciences).

\section{Protein electrophoresis and Western blotting}

Cells were harvested by scraping, homogenized, and analyzed by SDSPAGE followed by Western blotting using the indicated antibodies. Quantification was performed using ImageJ software (National Institutes of Health). The mean intensity of each individual band of interest was calculated after background value subtraction. Values were normalized to the mean intensity of the loading control band for each sample. To quantify phosphorylated GFP-MyoVI, the mean intensity of the phospho-GFP-MyoVI band was normalized to the total immunoprecipitated GFP-MyoVI.
SGs and cytosol purification from bovine adrenal medulla

Bovine adrenal medullas were fractionated as previously described (Simon et al., 1988; Meunier et al., 2005; Wen et al., 2011). In brief, isolated medullas were homogenized in $0.32 \mathrm{M}$ sucrose in $10 \mathrm{mM}$ Tris and $1 \mathrm{mM}$ EGTA, pH 7.4, and centrifuged $2 \times 15 \mathrm{~min}$ at $800 \mathrm{gav}_{\mathrm{av}}$. The supernatant was centrifuged again for $20 \mathrm{~min}$ at $12,000 \mathrm{gav}$, and the pellet 112,000 pellet) was resuspended in $0.32 \mathrm{M}$ sucrose in $10 \mathrm{mM}$ Tris and $1 \mathrm{mM}$ EGTA, $\mathrm{pH} 7.4$, and loaded on a linear sucrose gradient (34-68\%). After a 1-h centrifugation at $100,000 \mathrm{~g}_{\mathrm{av}}, 12 \times 1$-ml fractions were collected from the top of the gradient. To assess SG purification, $50 \mathrm{\mu g}$ of each fraction was analyzed by SDS-PAGE and Western blotting against markers of different subcellular compartments (Vitale et al., 1996). The supernatant from the $12,000 \mathrm{~g}_{\mathrm{av}}$ spin $(12 \mathrm{KSN})$ was further centrifuged for $1 \mathrm{~h}$ at $100,000 \mathrm{gav}_{\mathrm{a}}$, and the resulting supernatant was collected (100KSN). For the cytosol preparation, the 100KSN fraction was dialyzed overnight at $4^{\circ} \mathrm{C}$ in potassium glutamate buffer (KGEP buffer; $139 \mathrm{mM}$ potassium glutamate, $5 \mathrm{mM}$ glucose, $5 \mathrm{mM}$ EGTA, and $20 \mathrm{mM}$ Pipes- $\mathrm{NaOH}$, pH 6.8) containing $2 \mathrm{mM}$ of free $\mathrm{MgCl}_{2}, 2 \mathrm{mM}$ ATP, and 0 or $100 \mu \mathrm{M}$ of free $\mathrm{Ca}^{2+}$, calculated using the WEBMAXC program (Patton et al., 2004).

\section{$\mathrm{Ca}^{2+}$-dependent recruitment of myosin $\mathrm{VI}$ to SGs}

$100 \mu \mathrm{g}$ of purified SGs was incubated with $1 \mathrm{mg}$ cytosol for $30 \mathrm{~min}$ at $37^{\circ} \mathrm{C}$ in KGEP buffer containing $2 \mathrm{mM}$ of free $\mathrm{MgCl}_{2}, 2 \mathrm{mM} \mathrm{ATP}$, and the indicated free $\mathrm{Ca}^{2+}$ concentrations. Reactions were stopped by adding $750 \mu$ of ice-cold KGEP buffer containing the respective $\left[\mathrm{Ca}^{2+}\right]$, and SGs were isolated by ultracentrifugation for $45 \mathrm{~min}$ at $50,000 \mathrm{rpm}$ at $4{ }^{\circ} \mathrm{C}$. SG pellets were washed once with $250 \mu$ l of ice-cold KGEP buffer containing $\mathrm{Ca}^{2+}$ and then further ultracentrifuged for $45 \mathrm{~min}$ at $50,000 \mathrm{rpm}$ at $4{ }^{\circ} \mathrm{C}$. Pellets were resuspended in Laemmli sample buffer plus $\beta$-mercaptoethanol, mixed for $10 \mathrm{~min}$, and processed for SDS-PAGE and Western blotting.

\section{Pull-down of cytosolic proteins using SGs as bait and protein identification by MALDI-TOF/TOF-MS/MS}

Sample preparation. Chromaffin granules $(\sim 2 \mathrm{mg})$ were dissolved in $100 \mu$ of $2 \% \mathrm{wt} / \mathrm{vol}$ SDS (Sigma-Aldrich) at $55^{\circ} \mathrm{C}$ for $1 \mathrm{~h}$. Proteins were precipitated overnight with $1 \mathrm{ml}$ of $100 \%$ methanol at $-20^{\circ} \mathrm{C}$ and then pelleted at $16,000 \mathrm{~g}$ for $30 \mathrm{~min}$ at $4^{\circ} \mathrm{C}$ in a refrigerated microfuge $15415 \mathrm{R}$; Eppendorf). Pellets were washed carefully with $1 \mathrm{ml}$ of $-20^{\circ} \mathrm{C}$ methanol and allowed to air dry.

For analysis without protein normalization, pellets were reduced in $100 \mu \mathrm{l}$ of $2 \% \mathrm{wt} / \mathrm{vol}$ SDS, $50 \% \mathrm{vol} / \mathrm{vol}$ trifluoroethanol (TFE; SigmaAldrich), $0.1 \mathrm{M}$ ammonium bicarbonate (Sigma-Aldrich), $\mathrm{pH} 8$, and $10 \mathrm{mM}$ DTT (Sigma-Aldrich) at $65^{\circ} \mathrm{C}$ for $1 \mathrm{~h}$. Samples were alkylated by the addition of freshly prepared 0.5 M iodoacetamide (Sigma-Aldrich) to a final concentration of $50 \mathrm{mM}$ and incubated in the dark at $55^{\circ} \mathrm{C}$ for $1 \mathrm{~h}$.

Protein normalization was performed using an extensive modification of ProteoMiner (BioRad Laboratories). Protein pellets were resuspended in $50 \mu \mathrm{l}$ of $50 \% \mathrm{vol} / \mathrm{vol}$ TFE at $65^{\circ} \mathrm{C}$ for $1 \mathrm{~h}$, after which $50 \mu \mathrm{lPBS}$ was added to dilute the TFE concentration to $25 \%$ vol/vol. $40 \mu$ ProteoMiner resin slurry ( $20 \mu$ l of actual resin) was washed twice by vortexing with $1 \mathrm{ml}$ of water for $30 \mathrm{~s}$, with a brief spin in a capsule microfuge to pellet the resin. The resin was equilibrated by twice vortexing as described with PBS, after which $100 \mu$ l of sample in $25 \% \mathrm{vol} / \mathrm{vol}$ TFE was added to the $20 \mu \mathrm{l}$ of washed resin and incubated at $22^{\circ} \mathrm{C}$ for 90 min at the lowest speed in a benchtop vortex to keep the resin in suspension. The resin was then briefly pelleted in a capsule microfuge and washed twice with PBS and twice with water. Proteins were simultaneously eluted and reduced from the resin in $100 \mathrm{\mu l}$ of $2 \% \mathrm{wt} / \mathrm{vol}$ SDS, $50 \% \mathrm{vol} / \mathrm{vol}$ TFE, $0.1 \mathrm{M}$ ammonium bicarbonate, and $10 \mathrm{mMDTT}$ at $65^{\circ} \mathrm{C}$ for $1 \mathrm{~h}$. The resin was then pelleted, and the supernatant was transferred to a fresh tube, alkylated as by the addition of fresh $0.5 \mathrm{M}$ iodoacetamide to a final concentration of $50 \mathrm{mM}$, and incubated in the dark at $55^{\circ} \mathrm{C}$ for $1 \mathrm{~h}$.

under conditions described on the left. (C) GFP-MyoVI-SIfull and GFP-MyoVI-SIfull $\triangle$ DYD expression in PC12 cells were evaluated by Western blotting using the anti-myosin VI antibody. The arrow indicates the GFP-MyoVI proteins (175 kD). (D) PC12 cells coexpressing NPY-mCherry with GFP (control), GFPMyoVI-SIfull, or GFP-MyoVI-SIfull $\triangle D Y D$ were imaged by TIRF microscopy. NPY-mCherry-positive SGs were tracked after stimulation, and the average MSD during the first $40 \mathrm{~s}$ was plotted. (E) Average MSD at 40 s of tracking of NPY-mCherry-positive SGs. The results for control and GFP-MyoVI-SIfull-expressing cells are the same as those shown in Fig. 5 (D and E). (F) NPY-hPLAP release was evaluated using a double-stimulation protocol in PC12 cells expressing GFP (control), GFP-MyoVI-SIfull, or GFP-MyoVI-SIfull $\triangle$ DYD. Released NPY-hPLAP is expressed as a percentage of total NPY-hPLAP ( $n=3$ ). The results for control and GFP-MyoVI-SIfull-expressing cells are the same as those shown in Fig. 3 D. (G) NPY-hPLAP release was measured in wild-type (wt) PC12 cells and myosin VI stable knockdown (KD) PC12 cells expressing GFP (control) or GFP-MyoVI-SlfullDDYD (+GFP-MyoVI-Slfull $\triangle D Y D$ ). Released NPY-hPLAP is expressed as a percentage of rescue compared with wild-type PC 12 cells $(n=3)$. Bars: $(A$ and $B$, left $5 \mu \mathrm{m} ;(A$ and $B$, right) $1 \mu \mathrm{m}$. Error bars are means \pm SEM. ${ }^{*}, \mathrm{P}<0.05 ;{ }^{* *}, \mathrm{P}<0.01 ;{ }^{* *}, \mathrm{P}<0.001$ 
Trypsin digestion. Trypsin coprecipitation was performed by carefully adding $2 \mu \mathrm{l}$ of $1-\mathrm{mg} / \mathrm{ml}$ trypsin (Roche; modified sequencing grade in $5 \mathrm{mM}$ $\mathrm{HCl}$ ) to the side of the tube containing the reduced and alkylated proteins, washing the droplet into the sample using $1 \mathrm{ml}$ of $-20^{\circ} \mathrm{C}$ methanol, and allowing the sample and trypsin to coprecipitate overnight at $-20^{\circ} \mathrm{C}$ before pelleting and air drying. Trypsin digestion was performed by resuspending the pellet in $50 \mu \mathrm{l}$ of $0.1-\mathrm{M}$ ammonium bicarbonate, $\mathrm{pH} 8$, and incubating for $2 \mathrm{~h}$ at $37^{\circ} \mathrm{C}$. An additional $2 \mu \mathrm{l}$ of $1-\mathrm{mg} / \mathrm{ml}$ trypsin was added, and the sample was incubated for $4 \mathrm{~min}$ at the lowest power setting $(90 \mathrm{~W})$ in an inverter microwave to complete the digestion. Digestion was halted by the addition of $5 \mu \mathrm{l}$ of $5 \% \mathrm{vol} / \mathrm{vol}$ aqueous trifluoroacetic acid (TFA; Fluka)

HPLC. Samples were filtered through a $0.45-\mu \mathrm{m}$ centrifugal filter (Nanosep; Pall Corporation) at 16,000 g for $2 \mathrm{~min}$. HPLC was performed using an HPLC (UltiMate 3000; Dionex) with a 1:100 flow splitter for capillary HPLC flow rates. $5 \mu$ of the filtered sample was injected onto a 200- $\mu \mathrm{m} \times$ 50-mm monolithic polystyrene-divinylbenzene column (PepSwift; LC Packings) with an inline 200- $\mu \mathrm{m} \times 5$-mm monolithic trap column (LC Packings). The aqueous phase was $0.05 \%$ TFA in water. The mobile phase (B) was $0.045 \%$ TFA in $80: 20$ acetonitrile/water. Separation was performed at $65^{\circ} \mathrm{C}$ at a flow rate of $2.5 \mathrm{\mu l} / \mathrm{min}$. Gradient conditions were as follows: $0-10 \mathrm{~min}$ at $0 \% \mathrm{~B} ; 50 \mathrm{~min}$ at $25 \% \mathrm{~B} ; 80 \mathrm{~min}$ at $60 \% \mathrm{~B} ; 90-96 \mathrm{~min}$ at $100 \% \mathrm{~B}$; and $98-120$ min at $0 \% \mathrm{~B}$.

Matrix-assisted laser desorption ionization (MALDI) MS. HPLC eluates were automatically spotted onto polished steel MALDI targets (MTP 384; Bruker) at 15-s intervals using a MALDI spotting robot (Proteineer SP; Bruker). The sample was spotted 1:2 with diluted $\alpha$-cyano-4-hydroxycinnamic acid (CHCA; Bruker). The diluted matrix was prepared by 1:10 dilution of saturated CHCA in acetone (Sigma-Aldrich) into 6:3:1 ethanol (Sigma-Aldrich)/acetone/0.1\% TFA. The peptide calibration mixture (Bruker) was manually spotted onto the appropriate calibration positions. Targets were allowed to air dry for $30 \mathrm{~min}$ before loading into the ion source of the MALDI-time of flight (TOF)/TOF (Ultraflex III; Bruker). Automated data acquisition was performed using the Compass 1.3 suite of the software (FlexControl, FlexAnalysis, WarpLC, and BioTools; Bruker). MALDI-TOF-MS was performed in positive ion reflector mode with digitizing at $1 \mathrm{GHz}$ to allow acquisition with a laser rate of $200 \mathrm{~Hz}$ over the mass/charge $(\mathrm{m} / \mathrm{z})$ range of $900-3,500$. For each spot, 200 laser shots $(10 \times 20$ shots at random positions) were acquired at fixed laser intensity, with no fuzzy logic used for either laser intensity or data summation. Close external calibration was automatically performed using $\mathrm{MH}^{+}$ions of angiotensin $\mathrm{II}(\mathrm{m} / \mathrm{z}=$ $1,046.54)$, angiotensin I $(\mathrm{m} / \mathrm{z}=1,296.68)$, substance $P(\mathrm{~m} / \mathrm{z}=1,347.74)$, bombesin ( $\mathrm{m} / \mathrm{z}=1,619.82)$, adrenocorticotropic hormone $1-17(\mathrm{~m} / \mathrm{z}=$ $2,093.09)$, adrenocorticotropic hormone 18-39 (m/ $\mathrm{z}=2,465.20)$, and somatostatin 28 (m/z = 3, 147.47). MALDI-TOF/TOF-MS/MS (LIFT) was performed on parent ions selected by WarpLC. 200 laser shots were acquired in parent ion mode for which the laser power was increased by $70 \%$, and a further 800 shots were acquired in fragment ion mode. No fuzzy logic was used during the MS/MS acquisition. All LIFT was acquired at $200 \mathrm{~Hz}$ using a $1-\mathrm{GHz}$ digitizer rate.

Data processing. Each sample was separated twice by HPLC, and each target was analyzed twice by MALDI-TOF/TOF (LC-MALDI) for a total of four LC-MALDI datasets per sample. The four BTDX.xml files generated by WarpLC and BioTools, containing parent and fragment ion mass and intensity data for each run, were combined using an in-house algorithm to generate an averaged Mascot (Matrix Science) generic file (MGF) representative of the total peptides present in all four runs. The Mascot generic files of averaged data were used to perform an in-house Mascot search of the International Protein Index bovine database and SwissProt database (all taxa) using the following parameters: enzyme containing semitrypsin with two missed cleavages, fixed modifications of carbamidomethylcysteine, variable modifications of deamidated $N Q$ and oxidized $M$, peptide tolerance of $50 \mathrm{ppm}$, and MS/MS tolerance of 0.5 D. Mascot output was saved as a comma separated variable (CSV) file. Semiquantitative comparative analysis of calcium-treated $(+\mathrm{Ca})$ and untreated $(-\mathrm{Ca})$ data was performed using an in-house algorithm. In brief, the protein ID and Mascot score present in the CSV data from the $+\mathrm{Ca}$ and - Ca database searches were compared and separated into three classes: proteins uniquely identified in the +Ca search, proteins uniquely identified in the -Ca search, and "common" proteins identified in both searches. For each common protein, the $\log _{2}$ ratio (Mascot ratio) of its Mascot score from +Ca and - Ca was calculated. Individual Mascot ratios from all common proteins were then used to calculate a mean Mascot ratio and standard deviation. For each protein Mascot ratio, the number of standard deviations $(\sigma)$ from the mean ratio was calculated. Proteins with a $\sigma>2$ or less than -2 were considered to have a $95 \%$ significant difference in abundance between $+\mathrm{Ca}$ and - Ca samples. Data were combined into a CSV file for further analysis in a spreadsheet.

\section{GFP-MyoVI immunoprecipitation}

After $72 \mathrm{~h}$ of transfection with the indicated plasmids, PC 12 cells were treated with $0.1 \mathrm{mM}$ pervanadate in physiological saline solution (PSS) control buffer $(145 \mathrm{mM} \mathrm{NaCl}, 5.6 \mathrm{mM} \mathrm{KCl}, 0.5 \mathrm{mM} \mathrm{MgCl}$, $5.6 \mathrm{mM}$ glu-

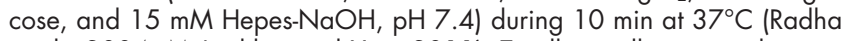
et al., 2004; McLachlan and Yap, 2011 ). To allow cell entry, sodium orthovanadate (vanadate) was combined with hydrogen peroxide to form peroxyvanadate (pervanadate). After treatment, cells were homogenized in ice-cold TNE buffer $15 \mathrm{mM}$ Tris, $\mathrm{pH} 7.5,140 \mathrm{mM} \mathrm{NaCl}$, and $5 \mathrm{mM}$ EDTA) containing complete protease and phosphatase inhibitor cocktails (Roche). Lysates were centrifuged for $5 \mathrm{~min}$ at $3,000 \mathrm{rpm}$ at $4^{\circ} \mathrm{C}$, and protein concentration was determined. $500 \mu \mathrm{g}$ protein was solubilized in radioimmunoprecipitation assay buffer $(50 \mathrm{mM}$ Tris- $\mathrm{HCl}, \mathrm{pH} 8,150 \mathrm{mM} \mathrm{NaCl}$, $1 \%$ NP-40, $0.5 \%$ deoxycholate, and $0.1 \%$ SDS) containing protease and phosphatase inhibitors by mixing at $4^{\circ} \mathrm{C}$ for $30 \mathrm{~min}$. After 5 min centrifugation at $15,000 \mathrm{rpm}$ at $4^{\circ} \mathrm{C}$, supernatants were incubated for $30 \mathrm{~min}$ with protein A/G agarose beads (Thermo Fisher Scientific) at $4^{\circ} \mathrm{C}$ to eliminate nonspecific binding. Samples were then centrifuged for $4 \mathrm{~min}$ at 15,000 rpm at $4^{\circ} \mathrm{C}$, after which the supernatants were incubated for $2 \mathrm{~h}$ at $4^{\circ} \mathrm{C}$ with the respective antibodies. Beads were added to the samples and further incubated for $1 \mathrm{~h}$ at $4^{\circ} \mathrm{C}$. Samples were then centrifuged for $2 \mathrm{~min}$ at $4^{\circ} \mathrm{C}$ at $15,000 \mathrm{rpm}$, and supernatants were kept for further analysis. The beads were washed in radioimmunoprecipitation assay buffer, resuspended in Laemmli sample buffer containing $\beta$-mercaptoethanol, and processed for SDS-PAGE and Western blotting.

\section{Myosin VI knockdown}

For transient myosin VI knockdown, PC12 cells were transfected twice at 24-h intervals using Lipofectamine LTX (Invitrogen) and shRNA constructs against rat myosin VI (XM_236444; obtained from the NCBI Nucleotide database) target sequences: clone 2 (sh2-RNA), 5'-AGATGACCTTCGAGTCAGTा-3'; clone 3 (sh3-RNA), 5'-AAGCGACTCGATAAGTCAAT-3'; and scrambled RNA (control), 5'-GGAATCTCATTCGATGCATAC-3' (SABiosciences). Each shRNA vector expressed GFP under a separate promoter. To generate stable myosin $\mathrm{VI}$ knockdown PC 12 cells, puromycinresistant sh2-RNA (SABiosciences) was used. Transfected cells were selected using $3 \mathrm{\mu g} / \mathrm{ml}$ puromycin for $3 \mathrm{wk}$ and subsequently maintained in $2.5 \mathrm{\mu g} / \mathrm{ml}$ puromycin. For TIRF experiments, PC 12 cells were transfected twice at 24-h intervals, with NPY-mCherry and control, sh2-RNA, or sh3-RNA plasmids as in this paragraph, and the cells were sorted using a cell sorter (Influx; BD). Sorted cells were analyzed by SDS-PAGE and Western blotting for myosin VI levels or plated on glass-bottomed culture dishes for imaging. For the NPY-hPLAP release assay, PC 12 cells were cotransfected twice at 24-h intervals with NPY-hPLAP and control, sh2-RNA, or sh3-RNA plasmids as in this paragraph. $48 \mathrm{~h}$ after the last transfection, myosin VI levels were determined by Western blotting, and NPY-hPLAP release assays were performed.

\section{Analysis of myosin VI splice variants by RT-PCR}

Total RNA was extracted from PC12 cells and rat liver using RNeasy mini kit (QIAGEN). Poly(A) ${ }^{+}$RNA was reverse transcribed, and PCR products were produced using the RT-PCR kit (ProtoScript M-MuLV Taq; New England Biolabs, Inc.). To amplify the regions of the myosin VI tail domain containing both the large inserts and Sls, the following primers were used: forward, 5'-GGAAGAGGAGTCCCAGCAG-3'; and reverse, 5'-CTGAGGGTCTTTGTACTGGT-3. To amplify $\beta$-actin, the following primers were used: forward, 5'-TCACCCACACTGTGCCCATCTATGA-3'; and reverse, 5'-TCAGGAGGAGCAATGATCTTGA-3'.

\section{NPY-hPLAP release assay}

Wild-type PC12 cells or myosin VI stable knockdown cells were transfected with NPY-hPLAP plasmid and the indicated constructs for $72 \mathrm{~h}$. Cells were washed and incubated with PSS buffer as a control $(145 \mathrm{mM} \mathrm{NaCl}, 5.6 \mathrm{mM}$ $\mathrm{KCl}, 0.5 \mathrm{mM} \mathrm{MgCl}$, $5.6 \mathrm{mM}$ glucose, and $15 \mathrm{mM}$ Hepes- $\mathrm{NaOH}$, pH 7.4) or stimulated with high $\mathrm{K}^{+}-\mathrm{PSS}$ buffer $(81 \mathrm{mM} \mathrm{NaCl}, 70 \mathrm{mM} \mathrm{KCl}, 2.2 \mathrm{mM}$ $\mathrm{CaCl}_{2}, 0.5 \mathrm{mM} \mathrm{MgCl}, 5.6 \mathrm{mM}$ glucose, and $15 \mathrm{mM}$ Hepes- $\mathrm{NaOH}$, $\mathrm{pH} \mathrm{7.4)} \mathrm{for} 15 \mathrm{~min}$ (first round of stimulation) at $37^{\circ} \mathrm{C}$. After this initial stimulation, the supernatants were collected, and the cells were washed and reincubated with PSS or high $\mathrm{K}^{+}-\mathrm{PSS}$ buffer for $45 \mathrm{~min}$ at $37^{\circ} \mathrm{C}$ (second round of stimulation). For time course experiments using a single high $\mathrm{K}^{+}$treatment $(60 \mathrm{~min}$ ) or double protocol of stimulation (as described in the previous paragraph), supernatants were collected every 5 or 10 min after the first simulation during the course of the experiment. After collecting the 
supernatants, cells were lysed with $0.2 \%$ Triton $X-100$ to measure total NPY-hPLAP. The released and total NPY-hPLAP were measured using the chemiluminescent reporter gene assay system (Phospha-Light; Applied Biosystems) according to the manufacturer's instructions, and the results were expressed as a percentage of total NPY-hPLAP.

\section{EM}

Immunogold labeling. PC12 cells seeded on poly-D-lysine-coated dishes were washed in PBS, fixed with $4 \%$ paraformaldehyde/PBS for $15 \mathrm{~min}$ and quenched with $50 \mathrm{mM} \mathrm{NHCl} / \mathrm{PBS}$ for $10 \mathrm{~min}$. They were then permeabilized in $0.1 \%$ Triton X-100/PBS for $10 \mathrm{~min}$ and blocked in $0.2 \%$ $\mathrm{BSA} / 0.2 \%$ fish skin gelatin/PBS for $10 \mathrm{~min}$. Cells were incubated for $60 \mathrm{~min}$ at room temperature with the anti-myosin VI antibody, washed with PBS, and labeled with protein $\mathrm{A}$ conjugated to 5 -nm gold particles. After labeling, cells were fixed with $2.5 \%$ glutaraldehyde and contrasted with $1 \%$ osmium tetroxide and $4 \%$ uranyl acetate before dehydration and embedding in LX-1 12 resin.

Correlative EM. PC 12 cells expressing GFP-MyoVI-SIfull were seeded on gridded poly-D-lysine-coated glass-bottomed culture dishes (MatTek Corporation). After $24 \mathrm{~h}$, cells were fixed in $2.5 \%$ glutaraldehyde in PBS Bright-field and epifluorescence images were taken using a 10x air objective on a microscope (Axio Imager; Carl Zeiss). The coordinates of transfected cells were noted before processing for transmission EM as in the previous paragraph.

For EM, sections $(\sim 50 \mathrm{~nm})$ were cut using an ultramicrotome (UC64 Leica) and imaged using a transmission electron microscope (mode 1011 ; JEOL) equipped with a cooled charge-coupled device camera (Morada; Olympus). All images were processed using Photoshop CS3 (Adobe), and figures were compiled with Illustrator CS3 (Adobe).

\section{Confocal microscopy}

Cells were imaged with a confocal microscope (LSM510 META; Carl Zeiss) using Zen acquisition software (2009 version; Carl Zeiss). Images were acquired with a Plan-Apochromat $63 \times$ oil immersion objective (NA 1.4). The pinhole was adjusted to obtain 1 Airy unit for the fluorophore of shortest wavelength excitation/emission properties. GFP or Alexa Fluor 488 fluorescence was detected using an argon laser with an excitation line at $488 \mathrm{~nm}$, a $488 / 561-\mathrm{nm}$ excitation dichroic mirror, and a 505/550-nm band pass emission filter. mCherry or Alexa Fluor 546 fluorescence was detected using a $561-n m$ excitation laser (power 0.5-2\%), a 488/561-nm excitation dichroic mirror, and a 575 -nm long pass emission filter. For dual color acquisition, images were sequentially acquired in line scan mode (average line $=4$ ).

Immunofluorescence confocal microscopy. Untransfected PC 12 cells or cells transfected with the plasmid of interest seeded on poly-D-lysine-coated coverslips were washed in PBS, fixed with $4 \%$ paraformaldehyde/PBS for $30 \mathrm{~min}$ on ice, and quenched with $50 \mathrm{mM} \mathrm{NHCl} / 4 / \mathrm{PBS}$ for $10 \mathrm{~min}$ on ice. Cells were then permeabilized in $0.1 \%$ saponin/2\% BSA/PBS for $10 \mathrm{~min}$ on ice and blocked in $0.2 \%$ BSA/0.2\% fish skin gelatin/PBS 10 min. Coverslips were incubated at $4{ }^{\circ} \mathrm{C}$ with primary antibodies overnight, washed with PBS, and treated with the relevant secondary antibodies for $1 \mathrm{~h}$ at $37^{\circ} \mathrm{C}$ followed by PBS washing and mounting with ProLong Gold (Molecular Probes; Invitrogen) for confocal imaging. Phalloidin staining (1:500; Molecular Probes; Invitrogen) was performed after cell fixation for $1 \mathrm{~h}$ at room temperature. For colocalization analysis, the Pearson correlation coefficient was determined using ImageJ, with the values being expressed as the means \pm SEM. To determine the area of the GFP-positive structures observed upon GFP-MyoVI-full protein expression in either wild-type or myosin VI knockdown PC12 cells, confocal images of fixed cells were used, and the area was measured using ImageJ. The results display the average of $\sim 150$ structures for each condition.

Live-cell imaging for activity-dependent recruitment of NPY-mCherrypositive vesicles around GFP-MyoVl-positive structures. Cells coexpressing NPY-mCherry and the respective GFP-MyoVI protein were washed and bathed in buffer $\mathrm{A}\left(145 \mathrm{mM} \mathrm{NaCl}, 5 \mathrm{mM} \mathrm{KCl}, 1.2 \mathrm{mM} \mathrm{Na}_{2} \mathrm{HPO}_{4}, 10 \mathrm{mM}\right.$ glucose, and $20 \mathrm{mM}$ Hepes- $\mathrm{NaOH}, \mathrm{pH} 7.4)$ containing $2 \mathrm{mM} \mathrm{Ca}^{2+}$ at room temperature. $Z$ stacks were taken over 10 min under control conditions and after $100 \mu M$ nicotine (Sigma-Aldrich) stimulation. Scan speed was $22 \mathrm{~s}$ /stack, and pinholes were adjusted to obtain an optical slice of $2 \mu \mathrm{m}$. Image analysis was performed using ImageJ software using raw nonsaturated images. A region of interest was drawn around GFP-MyoVIpositive structures, and the mean intensity was measured for both the GFP and $m$ Cherry channels for the duration of the video. Both intensities were expressed as a percentage of initial intensity and as means \pm SEM of three independent experiments.
Transferrin uptake. Cells expressing GFP-MyoVI proteins were incubated with transferrin-647 (1:500; Molecular Probes; Invitrogen) for $1 \mathrm{~h}$ at $37^{\circ} \mathrm{C}$ in serum-free DMEM. After washing in PBS, cells were fixed in $4 \%$ PFA/PBS, briefly rinsed in $\mathrm{H}_{2} \mathrm{O}$, and mounted using ProLong Gold for confocal imaging.

\section{TIRF microscopy}

After transfection, cells were visualized with a TIRF microscope (Marianas and Everest; Intelligent Imaging Innovations, Inc.) fitted with a $100 \times$ oil immersion objective (NA 1.46; Carl Zeiss) using an electron multiplying charge-coupled device camera (QuantEM 512SC; Photometrics) and SlideBook software (version 4.2.0.27/28; Intelligent Imaging Innovations, Inc.) for acquisition. Cells were bathed in buffer $\mathrm{A}$ before the addition of $100 \mu \mathrm{M}$ nicotine, and a time-lapse video using simultaneous acquisition was captured at 1 frame/s for the indicated period. The speed and density of NPY$\mathrm{mCherry-labeled} \mathrm{SGs}$ were measured using SlideBook (version 4.2.0.27/28) and ImageJ software. For long-term TIRF imaging, cells were bathed in PSS control buffer and imaged at 1 frame $/ 2 \mathrm{~s}$ for 40 min after stimulation with high $\mathrm{K}^{+}$-PSS buffer. To quantify the density of SGs, the average density of 40 frames per time point was measured using SlideBook (version 4.2.0.27/28) and ImageJ software. Particle tracking of NPY-mCherry-labeled SGs was performed on previously acquired TIRF images using the spottracking function of IMARIS (Version 7.3.1; Bitplane AG). SGs were tracked for $3 \mathrm{~min}$ after nicotine stimulation. The spot diameter was $0.48 \mu \mathrm{m}$, and vesicles were selected based on local contrast thresholding after background subtraction. Tracking was performed using the built-in autoregressive motion model with maximum displacement of $1 \mathrm{\mu m}$ per time step and a gap size of three frames. MSD was calculated for each vesicle over incrementing time intervals and then averaged (Steyer and Almers, 1999). To characterize SG mobility, MSD data were fitted to various diffusion models; best fits were obtained when a confined diffusion model was assumed (Saxton, 1993). In this model, the MSD is described as follows and provides a second order approximation of the SG diffusion within a finite space or cage:

$$
\operatorname{MSD}(\Delta t)=r_{c}^{2}\left\langle 1-A_{1} \times \exp \left(-\frac{4 A_{2} D}{r_{c}^{2}} \times \Delta t\right)\right\rangle .
$$

$A_{1}$ and $A_{2}$ are constants determined by the cage geometry with $A_{1}=0.99$ and $A_{2}=0.85$ for circular cages (Saxton, 1993; Saxton and Jacobson, 1997). $D$ is the diffusion coefficient of a particle within the cage, and $r$ is the radius of the circular cage in which an infinitesimally small particle is free to diffuse with diffusion coefficient $D_{\alpha}$. Only SGs tracked for $>10$ consecutive frames were considered.

To characterize the MSD of SGs moving toward the plasma membrane, the manual particle-tracking function from SlideBook software was used. These SGs can be identified as they appear in the TIRF plane, and their fluorescence intensity increases as they approach the plasma membrane. The trajectories of this population of SGs were followed after nicotine stimulation for 12-15 s, and the MSD for each track was calculated and averaged as stated in the previous paragraph. 40-80 trajectories were counted per condition. SGs already tethered in the TIRF plan were not included in this analysis.

To examine the possible change in SG movement upon association with GFP-MyoVI-full after stimulation, we used the colocalization module of SlideBook to identify GFP-MyoVI-positive or -negative NPY-mCherry-positive SGs. From the scatter plot obtained, the population of SGs with high fluorescence levels for the mCherry channel only was selected and considered as GFP-MyoVI-negative SGs. In addition, we also selected a population of SGs with high fluorescence levels for both mCherry and GFP. In this group, referred as GFP-MyoVI-positive SGs, we predominantly observed only partial colocalization between NPY-mCherry-labeled SGs and GFP-MyoVI, with GFP-MyoVI largely juxtapositioned to the SGs. 30-70 SGs were manvally tracked for $12 \mathrm{~s}$ for each condition, and the MSD was calculated for each trajectory.

\section{PP2 and PP3 treatments}

$\mathrm{PC} 12$ cells expressing the respective myosin $\mathrm{VI}$ proteins were washed and incubated with DMSO (control), $20 \mu M$ PP2, or $20 \mu$ M PP3 (EMD Millipore; Merck) in complete medium for $30 \mathrm{~min}$ at $37^{\circ} \mathrm{C}$. NPY-hPLAP release was subsequently assayed as described in the NPY-hPLAP release assay section in the continued presence of DMSO, $20 \mu \mathrm{M}$ PP2, or $20 \mu \mathrm{M}$ PP3. For livecell imaging, cells were washed and bathed in buffer $A$ in the presence of DMSO, $20 \mu \mathrm{M}$ PP2, or $20 \mu \mathrm{M}$ PP3. 


\section{Bioinformatics analysis}

Protein sequence alignments were performed using BLAST (Basic Local Alignment Search Tool). Phosphorylation sites and kinase-specific phosphorylation sites in myosin VI were predicted using NetPhos 2.0 (Center for Biological Sequence Analysis) and NetPhosK 1.0 (Center for Biological Sequence Analysis), respectively.

\section{Statistical analysis}

All experiments were repeated at least three times. Data analysis was performed using unpaired, two-tailed Student's $t$ tests, unless stated otherwise, and data were considered significant at $P<0.05$. Values are expressed as means $\pm S E M$, and the level of significance is designated in the figure legend as follows: ${ }^{*}, \mathrm{P}<0.05 ;{ }^{* *}, \mathrm{P}<0.01 ;{ }^{* *}, \mathrm{P}<0.001$.

\section{Online supplemental material}

Fig. S1 shows that myosin VI knockdown does not affect SG biogenesis or Golgi complex organization. Fig. S2 highlights the defect in SG replenishment near the plasma membrane in myosin $\mathrm{VI}$ knockdown $\mathrm{PC} 12$ cells. Fig. S3 shows that neither endocytic nor constitutive exocytic pathways are affected by the expression of GFP-MyoVI-full protein. Fig. S4 shows that GFP-MyoVIfull expression reorganizes SGs in an F-actin-dependent manner. Fig. S5 demonstrates that the potentiation of NPY-evoked release mediated by myosin VI SI requires c-Src kinase activity. Table S1 shows a selection of proteins identified using MALDI-TOF/TOF after pull-down experiment using purified SG. Video 1 (related to Fig. 4 E) shows that myosin VI SI restricts the movement of SGs near the plasma membrane. Video 2 (related to Fig. $4 \mathrm{~F}$ ) shows that the myosin $\mathrm{VI} \mathrm{NI}$ isoform lacks the ability to cage SG movement at the plasma membrane. Online supplemental material is available at http://www.jcb.org/cgi/content/full/jcb.201204092/DC1. Additional data are available in the JCB DataViewer at http://dx.doi .org/10.1083/jcb.201204092.dv.

EM was performed at the Australian Microscopy and Microanalysis Facility at the Centre for Microscopy and Microanalysis at the University of Queensland. We thank Dr. Alpha Yap and Dr. Brett Collins for gifting plasmids and antibodies and insightful discussions. We also give thanks to Luke Hammond for technical support with microscopy experiments and Rowan Tweedale for helpful comments on the manuscript.

This work was supported by a National Health and Medical Research Council (NHMRC) project grant and an Australian Research Council Linkage Infrastructure, Equipment and Facilities grant (LEO882864). F.A. Meunier is a Senior Research Fellow of the NHMRC. This work was also funded by the Wellcome Trust (F. Buss) and the Medical Research Council (J. Kendrick-Jones). The Cambridge Institute for Medical Research is in receipt of a strategic award from the Wellcome Trust.

Author contributions: V.M. Tomatis performed and analyzed most of the experiments. A. Papadopulos performed MSD and diffusion coefficient analysis from TIRF images. N.T. Malintan performed pull-down experiments. S. Martin performed EM experiments and contributed with intellectual input and discussion. T. Wallis performed and analyzed the MS experiments. R.S. Gormal performed RT-PCR and generated the NPY-mCherry and GFP-MyoVI-SIfull- $\triangle$ DYD constructs. V.M. Tomatis and F.A. Meunier conceived and designed the experiments and wrote the manuscript with input from S. Martin, J. KendrickJones, and F. Buss.

Submitted: 17 April 2012

Accepted: 7 January 2013

\section{References}

Ali, M.Y., G.G. Kennedy, D. Safer, K.M. Trybus, H.L. Sweeney, and D.M. Warshaw. 2011. Myosin Va and myosin VI coordinate their steps while engaged in an in vitro tug of war during cargo transport. Proc. Natl. Acad. Sci. USA. 108:E535-E541. http://dx.doi.org/10.1073/pnas.1104298108

Aschenbrenner, L., T. Lee, and T. Hasson. 2003. Myo6 facilitates the translocation of endocytic vesicles from cell peripheries. Mol. Biol. Cell. 14:2728-2743. http://dx.doi.org/10.1091/mbc.E02-11-0767

Au, J.S., C. Puri, G. Ihrke, J. Kendrick-Jones, and F. Buss. 2007. Myosin VI is required for sorting of AP-1B-dependent cargo to the basolateral domain in polarized MDCK cells. J. Cell Biol. 177:103-114. http://dx.doi .org/10.1083/jcb.200608126

Bader, M.F., R.W. Holz, K. Kumakura, and N. Vitale. 2002. Exocytosis: the chromaffin cell as a model system. Ann. NY Acad. Sci. 971:178-183. http://dx.doi.org/10.1111/j.1749-6632.2002.tb04461.x
Bain, J., H. McLauchlan, M. Elliott, and P. Cohen. 2003. The specificities of protein kinase inhibitors: an update. Biochem. J. 371:199-204. http://dx.doi .org/10.1042/BJ20021535

Becherer, U., and J. Rettig. 2006. Vesicle pools, docking, priming, and release. Cell Tissue Res. 326:393-407. http://dx.doi.org/10.1007/s00441-006-0243-z

Bellei, E., E. Monari, S. Bergamini, T. Ozben, and A. Tomasi. 2011. Optimizing protein recovery yield from serum samples treated with beads technology. Electrophoresis. 32:1414-1421. http://dx.doi.org/10.1002/elps .201000699

Bond, L.M., A.A. Peden, J. Kendrick-Jones, J.R. Sellers, and F. Buss. 2011. Myosin VI and its binding partner optineurin are involved in secretory vesicle fusion at the plasma membrane. Mol. Biol. Cell. 22:54-65. http:/ dx.doi.org/10.1091/mbc.E10-06-0553

Brose, N., A.G. Petrenko, T.C. Südhof, and R. Jahn. 1992. Synaptotagmin: a calcium sensor on the synaptic vesicle surface. Science. 256:1021-1025. http://dx.doi.org/10.1126/science.1589771

Bryant, Z., D. Altman, and J.A. Spudich. 2007. The power stroke of myosin VI and the basis of reverse directionality. Proc. Natl. Acad. Sci. USA. 104:772-777. http://dx.doi.org/10.1073/pnas.0610144104

Buss, F., and J. Kendrick-Jones. 2008. How are the cellular functions of myosin VI regulated within the cell? Biochem. Biophys. Res. Commun. 369:165-175. http://dx.doi.org/10.1016/j.bbrc.2007.11.150

Buss, F., J. Kendrick-Jones, C. Lionne, A.E. Knight, G.P. Côté, and J. Paul Luzio. 1998. The localization of myosin VI at the Golgi complex and leading edge of fibroblasts and its phosphorylation and recruitment into membrane ruffles of A431 cells after growth factor stimulation. J. Cell Biol. 143:1535-1545. http://dx.doi.org/10.1083/jcb.143.6.1535

Buss, F., S.D. Arden, M. Lindsay, J.P. Luzio, and J. Kendrick-Jones. 2001. Myosin VI isoform localized to clathrin-coated vesicles with a role in clathrin-mediated endocytosis. EMBO J. 20:3676-3684. http://dx.doi .org/10.1093/emboj/20.14.3676

Chasserot-Golaz, S., N. Vitale, E. Umbrecht-Jenck, D. Knight, V. Gerke, and M.F. Bader. 2005. Annexin 2 promotes the formation of lipid microdomains required for calcium-regulated exocytosis of dense-core vesicles. Mol. Biol. Cell. 16:1108-1119. http://dx.doi.org/10.1091/mbc .E04-07-0627

Dernick, G., G. Alvarez de Toledo, and M. Lindau. 2003. Exocytosis of single chromaffin granules in cell-free inside-out membrane patches. Nat. Cell Biol. 5:358-362. http://dx.doi.org/10.1038/ncb956

Desnos, C., S. Huet, I. Fanget, C. Chapuis, C. Böttiger, V. Racine, J.B. Sibarita, J.P. Henry, and F. Darchen. 2007. Myosin va mediates docking of secretory granules at the plasma membrane. J. Neurosci. 27:10636-10645. http://dx.doi.org/10.1523/JNEUROSCI.1228-07.2007

Eichler, T.W., T. Kögel, N.V. Bukoreshtliev, and H.H. Gerdes. 2006. The role of myosin Va in secretory granule trafficking and exocytosis. Biochem. Soc. Trans. 34:671-674. http://dx.doi.org/10.1042/BST0340671

Fonslow, B.R., P.C. Carvalho, K. Academia, S. Freeby, T. Xu, A. Nakorchevsky, A. Paulus, and J.R. Yates III. 2011. Improvements in proteomic metrics of low abundance proteins through proteome equalization using ProteoMiner prior to MudPIT. J. Proteome Res. 10:3690-3700. http:// dx.doi.org/10.1021/pr200304u

Gasman, S., S. Chasserot-Golaz, M. Malacombe, M. Way, and M.F. Bader. 2004. Regulated exocytosis in neuroendocrine cells: a role for subplasmalemmal Cdc42/N-WASP-induced actin filaments. Mol. Biol. Cell. 15:520-531. http://dx.doi.org/10.1091/mbc.E03-06-0402

Gurd, J.W. 1997. Protein tyrosine phosphorylation: implications for synaptic function. Neurochem. Int. 31:635-649. http://dx.doi.org/10.1016/ S0197-0186(97)00022-3

Hanke, J.H., J.P. Gardner, R.L. Dow, P.S. Changelian, W.H. Brissette, E.J. Weringer, B.A. Pollok, and P.A. Connelly. 1996. Discovery of a novel, potent, and Src family-selective tyrosine kinase inhibitor. Study of Lckand FynT-dependent T cell activation. J. Biol. Chem. 271:695-701. http://dx.doi.org/10.1074/jbc.271.2.695

Ingley, E. 2008. Src family kinases: regulation of their activities, levels and identification of new pathways. Biochim. Biophys. Acta. 1784:56-65. http:// dx.doi.org/10.1016/j.bbapap.2007.08.012

Jiang, R., B. Gao, K. Prasad, L.E. Greene, and E. Eisenberg. 2000. Hsc70 chaperones clathrin and primes it to interact with vesicle membranes. J. Biol. Chem. 275:8439-8447. http://dx.doi.org/10.1074/jbc.275.12.8439

Jordan, M.A., and L. Wilson. 1998. Use of drugs to study role of microtubule assembly dynamics in living cells. Methods Enzymol. 298:252-276. http://dx.doi.org/10.1016/S0076-6879(98)98024-7

Keller, P., D. Toomre, E. Díaz, J. White, and K. Simons. 2001. Multicolour imaging of post-Golgi sorting and trafficking in live cells. Nat. Cell Biol. 3:140-149. http://dx.doi.org/10.1038/35055042

Kisiel, M., D. Majumdar, S. Campbell, and B.A. Stewart. 2011. Myosin VI contributes to synaptic transmission and development at the Drosophila 
neuromuscular junction. BMC Neurosci. 12:65. http://dx.doi.org/10 $.1186 / 1471-2202-12-65$

Kögel, T., R. Rudolf, E. Hodneland, A. Hellwig, S.A. Kuznetsov, F. Seiler, T.H. Söllner, J. Barroso, and H.H. Gerdes. 2010. Distinct roles of myosin Va in membrane remodeling and exocytosis of secretory granules. Traffic. 11:637-650. http://dx.doi.org/10.1111/j.1600-0854.2010.01048.x

Krendel, M., and M.S. Mooseker. 2005. Myosins: tails (and heads) of functional diversity. Physiology (Bethesda). 20:239-251. http://dx.doi.org/ 10.1152/physiol.00014.2005

Lejen, T., T.D. Pene, S.D. Rosé, and J.M. Trifaró. 2002. The role of different Scinderin domains in the control of F-actin cytoskeleton during exocytosis. Ann. NY Acad. Sci. 971:248-250. http://dx.doi.org/10.1111/ j.1749-6632.2002.tb04469.x

Linstedt, A.D., M.L. Vetter, J.M. Bishop, and R.B. Kelly. 1992. Specific association of the proto-oncogene product pp60c-src with an intracellular organelle, the PC12 synaptic vesicle. J. Cell Biol. 117:1077-1084. http:// dx.doi.org/10.1083/jcb.117.5.1077

Majewski, L., M. Sobczak, and M.J. Redowicz. 2010. Myosin VI is associated with secretory granules and is present in the nucleus in adrenal medulla chromaffin cells. Acta Biochim. Pol. 57:109-114.

Majewski, L., M. Sobczak, A. Wasik, K. Skowronek, and M.J. Rędowicz. 2011. Myosin VI in PC12 cells plays important roles in cell migration and proliferation but not in catecholamine secretion. J. Muscle Res. Cell Motil. 32:291-302. http://dx.doi.org/10.1007/s10974-011-9279-0

Malacombe, M., M. Ceridono, V. Calco, S. Chasserot-Golaz, P.S. McPherson, M.F. Bader, and S. Gasman. 2006. Intersectin-1L nucleotide exchange factor regulates secretory granule exocytosis by activating Cdc42. EMBO J. 25:3494-3503. http://dx.doi.org/10.1038/sj.emboj.7601247

McLachlan, R.W., and A.S. Yap. 2011. Protein tyrosine phosphatase activity is necessary for E-cadherin-activated Src signaling. Cytoskeleton (Hoboken). $68: 32-43$.

McLachlan, R.W., A. Kraemer, F.M. Helwani, E.M. Kovacs, and A.S. Yap. 2007. E-cadherin adhesion activates c-Src signaling at cell-cell contacts. Mol. Biol. Cell. 18:3214-3223. http://dx.doi.org/10.1091/mbc.E06-12-1154

Mermall, V., P.L. Post, and M.S. Mooseker. 1998. Unconventional myosins in cell movement, membrane traffic, and signal transduction. Science. 279:527-533. http://dx.doi.org/10.1126/science.279.5350.527

Messa, M., S. Congia, E. Defranchi, F. Valtorta, A. Fassio, F. Onofri, and F. Benfenati. 2010. Tyrosine phosphorylation of synapsin I by Src regulates synaptic-vesicle trafficking. J. Cell Sci. 123:2256-2265. http://dx.doi .org/10.1242/jcs.068445

Meunier, F.A., S.L. Osborne, G.R. Hammond, F.T. Cooke, P.J. Parker, J. Domin, and G. Schiavo. 2005. Phosphatidylinositol 3-kinase C2 $\alpha$ is essential for ATP-dependent priming of neurosecretory granule exocytosis. Mol. Biol. Cell. 16:4841-4851. http://dx.doi.org/10.1091/mbc.E05-02-0171

Nakata, T., and N. Hirokawa. 1992. Organization of cortical cytoskeleton of cultured chromaffin cells and involvement in secretion as revealed by quickfreeze, deep-etching, and double-label immunoelectron microscopy. J. Neurosci. 12:2186-2197.

Neher, E. 2006. A comparison between exocytic control mechanisms in adrenal chromaffin cells and a glutamatergic synapse. Pflugers Arch. 453: 261-268. http://dx.doi.org/10.1007/s00424-006-0143-9

Oheim, M., and W. Stühmer. 2000. Tracking chromaffin granules on their way through the actin cortex. Eur. Biophys. J. 29:67-89. http://dx.doi .org/10.1007/s002490050253

Ohnishi, H., S. Yamamori, K. Ono, K. Aoyagi, S. Kondo, and M. Takahashi. 2001. A src family tyrosine kinase inhibits neurotransmitter release from neuronal cells. Proc. Natl. Acad. Sci. USA. 98:10930-10935. http:// dx.doi.org/10.1073/pnas.191368198

Onofri, F., S. Giovedì, P. Vaccaro, A.J. Czernik, F. Valtorta, P. De Camilli, P. Greengard, and F. Benfenati. 1997. Synapsin I interacts with c-Src and stimulates its tyrosine kinase activity. Proc. Natl. Acad. Sci. USA. 94:12168-12173. http://dx.doi.org/10.1073/pnas.94.22.12168

Osborne, S.L., P.J. Wen, C. Boucheron, H.N. Nguyen, M. Hayakawa, H. Kaizawa, P.J. Parker, N. Vitale, and F.A. Meunier. 2008. PIKfyve negatively regulates exocytosis in neurosecretory cells. J. Biol. Chem. 283:2804-2813. http://dx.doi.org/10.1074/jbc.M704856200

Pang, D.T., J.K. Wang, F. Valtorta, F. Benfenati, and P. Greengard. 1988. Protein tyrosine phosphorylation in synaptic vesicles. Proc. Natl. Acad. Sci. USA. 85:762-766. http://dx.doi.org/10.1073/pnas.85.3.762

Papini, E., O. Rossetto, and D.F. Cutler. 1995. Vesicle-associated membrane protein (VAMP)/synaptobrevin-2 is associated with dense core secretory granules in PC12 neuroendocrine cells. J. Biol. Chem. 270:1332-1336. http://dx.doi.org/10.1074/jbc.270.3.1332

Patton, C., S. Thompson, and D. Epel. 2004. Some precautions in using chelators to buffer metals in biological solutions. Cell Calcium. 35:427-431. http://dx.doi.org/10.1016/j.ceca.2003.10.006
Prekeris, R., and D.M. Terrian. 1997. Brain myosin V is a synaptic vesicleassociated motor protein: evidence for a $\mathrm{Ca}^{2+}$-dependent interaction with the synaptobrevin-synaptophysin complex. J. Cell Biol. 137:1589-1601. http://dx.doi.org/10.1083/jcb.137.7.1589

Puri, C. 2009. Loss of myosin VI no insert isoform (NoI) induces a defect in clathrin-mediated endocytosis and leads to caveolar endocytosis of transferrin receptor. J. Biol. Chem. 284:34998-35014. http://dx.doi.org/ 10.1074/jbc.M109.012328

Radha, V., A. Rajanna, and G. Swarup. 2004. Phosphorylated guanine nucleotide exchange factor $\mathrm{C} 3 \mathrm{G}$, induced by pervanadate and Src family kinases localizes to the Golgi and subcortical actin cytoskeleton. BMC Cell Biol. 5:31. http://dx.doi.org/10.1186/1471-2121-5-31

Riedl, J., A.H. Crevenna, K. Kessenbrock, J.H. Yu, D. Neukirchen, M. Bista, F. Bradke, D. Jenne, T.A. Holak, Z. Werb, et al. 2008. Lifeact: a versatile marker to visualize F-actin. Nat. Methods. 5:605-607. http://dx.doi .org/10.1038/nmeth.1220

Roberts, R., I. Lister, S. Schmitz, M. Walker, C. Veigel, J. Trinick, F. Buss, and J. Kendrick-Jones. 2004. Myosin VI: cellular functions and motor properties. Philos. Trans. R. Soc. Lond. B Biol. Sci. 359:1931-1944. http:// dx.doi.org/10.1098/rstb.2004.1563

Rodriguez Del Castillo, A., S. Lemaire, L. Tchakarov, M. Jeyapragasan, J.P. Doucet, M.L. Vitale, and J.M. Trifaró. 1990. Chromaffin cell scinderin, a novel calcium-dependent actin filament-severing protein. EMBO J. 9:43-52.

Rothman, J.E. 1989. Polypeptide chain binding proteins: catalysts of protein folding and related processes in cells. Cell. 59:591-601. http://dx.doi .org/10.1016/0092-8674(89)90005-6

Rudolf, R., T. Kögel, S.A. Kuznetsov, T. Salm, O. Schlicker, A. Hellwig, J.A. Hammer III, and H.H. Gerdes. 2003. Myosin Va facilitates the distribution of secretory granules in the F-actin rich cortex of PC12 cells. J. Cell Sci. 116:1339-1348. http://dx.doi.org/10.1242/jcs.00317

Rusanescu, G., H. Qi, S.M. Thomas, J.S. Brugge, and S. Halegoua. 1995. Calcium influx induces neurite growth through a Src-Ras signaling cassette. Neuron. 15:1415-1425. http://dx.doi.org/10.1016/08966273(95)90019-5

Sarafian, T., L.A. Pradel, J.P. Henry, D. Aunis, and M.F. Bader. 1991. The participation of annexin II (calpactin I) in calcium-evoked exocytosis requires protein kinase C. J. Cell Biol. 114:1135-1147. http://dx.doi .org/10.1083/jcb.114.6.1135

Saxton, M.J. 1993. Lateral diffusion in an archipelago. Single-particle diffusion. Biophys. J. 64:1766-1780. http://dx.doi.org/10.1016/S0006-3495 (93)81548-0

Saxton, M.J., and K. Jacobson. 1997. Single-particle tracking: applications to membrane dynamics. Annu. Rev. Biophys. Biomol. Struct. 26:373-399. http://dx.doi.org/10.1146/annurev.biophys.26.1.373

Schwartz, D., and S.P. Gygi. 2005. An iterative statistical approach to the identification of protein phosphorylation motifs from large-scale data sets. Nat. Biotechnol. 23:1391-1398. http://dx.doi.org/10.1038/nbt1146

Self, T., T. Sobe, N.G. Copeland, N.A. Jenkins, K.B. Avraham, and K.P. Steel. 1999. Role of myosin VI in the differentiation of cochlear hair cells. Dev. Biol. 214:331-341. http://dx.doi.org/10.1006/dbio.1999.9424

Shyu, K.G., G.M. Jow, Y.J. Lee, and S.J. Wang. 2005. PP2 inhibits glutamate release from nerve endings by affecting vesicle mobilization. Neuroreport. 16:1969-1972. http://dx.doi.org/10.1097/01.wnr .0000189758 .57164 .85

Simon, J.P., M.F. Bader, and D. Aunis. 1988. Secretion from chromaffin cells is controlled by chromogranin A-derived peptides. Proc. Natl. Acad. Sci. USA. 85:1712-1716. http://dx.doi.org/10.1073/pnas.85.5.1712

Smith, A.D., and H. Winkler. 1967. A simple method for the isolation of adrenal chromaffin granules on a large scale. Biochem. J. 103:480-482.

Spector, I., N.R. Shochet, Y. Kashman, and A. Groweiss. 1983. Latrunculins: novel marine toxins that disrupt microfilament organization in cultured cells. Science. 219:493-495. http://dx.doi.org/10.1126/science .6681676

Steyer, J.A., and W. Almers. 1999. Tracking single secretory granules in live chromaffin cells by evanescent-field fluorescence microscopy. Biophys. J. 76:2262-2271. http://dx.doi.org/10.1016/S0006-3495(99)77382-0

Toonen, R.F., O. Kochubey, H. de Wit, A. Gulyas-Kovacs, B. Konijnenburg, J.B. Sørensen, J. Klingauf, and M. Verhage. 2006. Dissecting docking and tethering of secretory vesicles at the target membrane. EMBO J. 25:3725-3737. http://dx.doi.org/10.1038/sj.emboj.7601256

Trifaró, J.M., and M.L. Vitale. 1993. Cytoskeleton dynamics during neurotransmitter release. Trends Neurosci. 16:466-472. http://dx.doi.org/ 10.1016/0166-2236(93)90079-2

Turner, K.M., R.D. Burgoyne, and A. Morgan. 1999. Protein phosphorylation and the regulation of synaptic membrane traffic. Trends Neurosci. 22:459-464. http://dx.doi.org/10.1016/S0166-2236(99)01436-8 
Varadi, A., T. Tsuboi, and G.A. Rutter. 2005. Myosin Va transports dense core secretory vesicles in pancreatic MIN6 $\beta$-cells. Mol. Biol. Cell. 16: 2670-2680. http://dx.doi.org/10.1091/mbc.E04-11-1001

Vitale, M.L., A. Rodríguez Del Castillo, L. Tchakarov, and J.M. Trifaró. 1991. Cortical filamentous actin disassembly and scinderin redistribution during chromaffin cell stimulation precede exocytosis, a phenomenon not exhibited by gelsolin. J. Cell Biol. 113:1057-1067. http://dx.doi.org/ 10.1083/jcb.113.5.1057

Vitale, N., M. Gensse, S. Chasserot-Golaz, D. Aunis, and M.F. Bader. 1996. Trimeric $\mathrm{G}$ proteins control regulated exocytosis in bovine chromaffin cells: sequential involvement of Go associated with secretory granules and Gi3 bound to the plasma membrane. Eur. J. Neurosci. 8:1275-1285. http://dx.doi.org/10.1111/j.1460-9568.1996.tb01296.x

Wang, S.J. 2003. A role for Src kinase in the regulation of glutamate release from rat cerebrocortical nerve terminals. Neuroreport. 14:1519-1522. http://dx.doi.org/10.1097/00001756-200308060-00024

Wells, A.L., A.W. Lin, L.Q. Chen, D. Safer, S.M. Cain, T. Hasson, B.O. Carragher, R.A. Milligan, and H.L. Sweeney. 1999. Myosin VI is an actin-based motor that moves backwards. Nature. 401:505-508. http:// dx.doi.org/10.1038/46835

Wen, P.J., S.L. Osborne, M. Zanin, P.C. Low, H.T. Wang, S.M. Schoenwaelder, S.P. Jackson, R. Wedlich-Söldner, B. Vanhaesebroeck, D.J. Keating, and F.A. Meunier. 2011. Phosphatidylinositol(4,5)bisphosphate coordinates actin-mediated mobilization and translocation of secretory vesicles to the plasma membrane of chromaffin cells. Nat Commun. 2:491. http://dx.doi .org/10.1038/ncomms 1500

Westerink, R.H., and A.G. Ewing. 2008. The PC12 cell as model for neurosecretion. Acta Physiol. (Oxf.). 192:273-285. http://dx.doi.org/10.1111/ j.1748-1716.2007.01805.x 